\title{
Les levains lactiques thermophiles : \\ Propriétés et comportement en technologie laitière.
}

\author{
Une revue *
}

par

J. P. Accolas**, D. Hemme**, M. J. Desmazeaud**, L. VASSaL ${ }^{* * *}$, C. Bouillanne** et Monique Veaux**

\section{SOMMAIRE}

INTRODUCTION $\ldots \begin{array}{llllllllllllllllllllll} & \ldots & \ldots & \ldots & \ldots & \ldots & \ldots & \ldots & \ldots & \ldots & \ldots & \ldots & \ldots & \ldots & \ldots & & 488\end{array}$

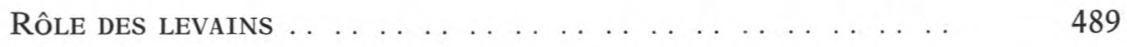

TAXONOMIE DES BACTÉRIES LACTIQUES THERMOPHILES . . . . . . 491

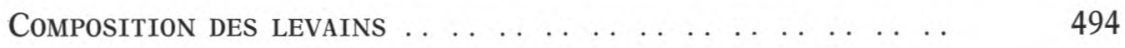

- Levains artisanaux

- Levains sélectionnés

Utilisation DE LEVAINS LACTIQUES THERMOPHILES CONCENTRÉS 496

A. Le yoghourt . . . . . . . . . . . . $\quad 499$

INFLUENCE DE LA QUALITÉ DU LAIT

- Le chauffage du lait

* Ce texte constitue une version revue et complétée d'une conférence présentée par l'un des auteurs (J. P. Accolas) au Congrès International de Microbiologie et d'Industrie Alimentaire, organisé par l'APRIA, Hôtel Méridien, Paris, le jeudi 11 octobre 1979 .

** Laboratoire de Microbiologie Laitière et de Génie Alimentaire et *** Laboratoire de Biochimie et de Technologie Laitières, I.N.R.A. - 78350 Jouy-en-Josas. 
PROPRIÉTÉS DES BACTÉRIES DU YOGHOURT

- Fermentation du lactose

- Production d'arôme

- Synergie des bactéries du yoghourt

FERMENTATION LACTIQUE CONTINUE APPLIQUÉE A LA FABRICATION DU YOGHOURT

B. Les fromages a PATE cuite . . . . . . .

MÉCANISME DE L'ÉGOUTTAgE

RôLE DU LEVAIN LACTIQUE THERMOPHILE AU COURS DE L'AFFINAGE

- Action protéolytique des bactéries lactiques thermophiles. Données générales

- Action protéolytique du levain lactique thermophile au cours de l'affinage de l'emmental

C. BACTÉRIOPHAGES . . $\ldots \ldots \ldots$

\section{INTRODUCTION}

Les bactéries lactiques des levains thermophiles, comme celles des levains lactiques mésophiles (Cogan [24]), ont été utilisées pour la fabrication du fromage et des laits fermentés bien avant qu'on soupçonnât leur existence. Cela dit, on doit remarquer d'entrée qu'il existe, dans le cas des fromages à pâte cuite, deux secteurs de production sensiblement différents. Le secteur traditionnel présente encore, mutatis mutandis, des caractéristiques proches des techniques artisanales d'antan. C'est par exemple le cas des fromageries de la zone d'origine, dans les montagnes du Jura et des Alpes (Mocquot [62]).

La fabrication industrielle de ce type de fromage, qui implique la transformation quotidienne d'importantes quantités de lait (plusieurs centaines de milliers de litres) dans de grandes usines faisant appel à une mécanisation poussée, s'est développée hors de la zone traditionnelle, par exemple aux Etats-Unis (Swiss cheese), en Finlande et, plus récemment, dans l'Ouest de la France, en Bretagne et en Normandie. De même, le yoghourt constitue un bon exemple de produit de grande consommation qui a connu un essor industriel sans précédent au cours des 3 dernières décennies, dans de nombreux pays d'Europe et d'Amérique (Auclair et Mocquot [11] ; Robinson et Tamine [77]).

Cela dit, pour traiter des levains lactiques thermophiles, il importe de se fixer au départ certaines limites, car le champ d'investigations est vaste. En outre, il convient de choisir l'approche du sujet. Dans le cadre de cette revue de microbiologie appliquée, il nous a semblé 
opportun de voir dans quelle mesure la technologie laitière est capable de maîtriser les levains lactiques thermophiles, pour obtenir des produits de qualité uniforme et régulière. Cela nous conduira à examiner successivement ce que sont ces levains, leurs caractéristiques et leurs propriétés et enfin leur comportement en nous appuyant sur deux types de produits, à divers titres intéressants pour le microbiologiste, le yoghourt et les fromages à pâte cuite (emmental et gruyère). On retiendra toutefois que des levains lactiques thermophiles sont utilisés pour fabriquer de nombreux autres types de fromages, plus ou moins égouttés, par exemple des fromages italiens aussi différents que le gorgonzola et le grana. En outre, Streptococcus thermophilus est également utilisé pour fabriquer certains types de fromages à pâte molle, en remplacement des levains lactiques mésophiles. Les propriétés acidifiantes et protéolytiques de ce streptocoque thermophile sont suffisamment différentes de celles des streptocoques lactiques du groupe $\mathrm{N}$ pour conférer aux produits obtenus des caractéristiques bien particulières.

\section{ROLE DES LEVAINS LACTIQUES THERMOPHILES}

Schématiquement, on peut assigner deux fonctions à ces levains :

- la première est d'assurer la transformation du lactose en acide lactique et, ce faisant, d'abaisser le $\mathrm{pH}$ du lait et du caillé de fromagerie. Ce rôle est déterminant dans le cas du yoghourt dont le $\mathrm{pH}$ final se situe à une valeur $\leqslant 4$, car il empêche le développement de germes indésirables (producteurs de gaz, putréfiants) et de germes pathogènes éventuellement présents. Dans le cas des fromages à pâte cuite, l'acidification (plus modérée en raison du pouvoir tampon du caillé) va cependant favoriser la synérèse, c'est-à-dire permettre une expulsion de l'eau du caillé, en quantité déterminée et au moment opportun (c'est l'égouttage du fromage sous presse). On obtiendra ainsi un extrait sec suffisamment élevé et un $\mathrm{pH}$ suffisamment bas pour que le fromage puisse ensuite subir, avec succès, une longue période d'affinage (plusieurs mois) ;

- la seconde est de contribuer aux qualités organoleptiques du produit obtenu. Dans le cas du yoghourt, ce rôle est primordial puisque la consistance, le goût et l'arôme de ce lait fermenté proviennent, pour une part essentielle, du métabolisme du levain lactique. Dans le cas des fromages, les cellules bactériennes vont libérer des systèmes enzymatiques qui participeront à l'affinage, conjointement avec la présure. Ainsi, à des degrés divers selon le type de produit, la protéolyse va modifier les propriétés rhéologiques du fromage et donner naissance à des composés sapides ou à des précurseurs d'arôme qui, repris éventuellement par d'autres micro-organismes ou modifiés par des réactions purement chimiques (c'est l'hypothèse avancée par Law et al. [53] dans le cas du cheddar) donneront au fromage affiné ses caractéristiques organoleptiques propres. 
TABLEAU 1

Principaux caractères de $S$. thermophilus*

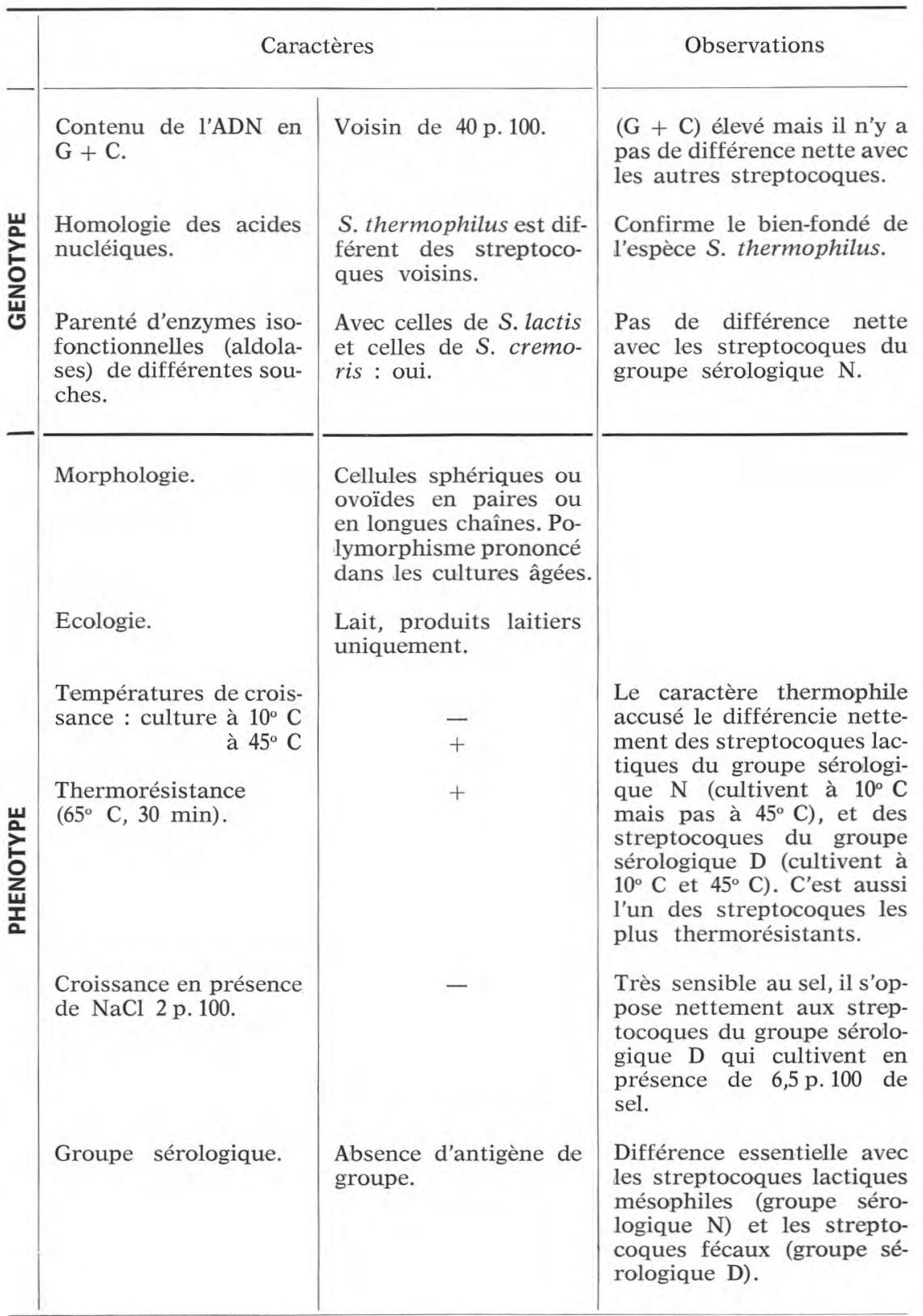

* Voir à la fin du tableau 1, page suivante. 
TABLEAU 1 (suite)

\begin{tabular}{|c|c|c|c|}
\hline \multirow{4}{*}{ 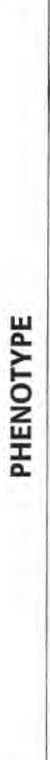 } & \multicolumn{2}{|c|}{ Caractères } & Observations \\
\hline & Hydrolyse de l'arginine. & - & $\begin{array}{l}\text { S. lactis et la plupart des } \\
\text { streptocoques du groupe } \\
\text { sérologique D sont positifs. }\end{array}$ \\
\hline & $\begin{array}{l}\text { Sucres fermentés : } \\
\text { - fructose, glucose, lac- } \\
\text { tose, saccharose, } \\
\text { - maltose, pentoses } \\
\text { (xylose et arabinose) } \\
\text { et raffinose, } \\
\text { tréhalose, inuline, } \\
\text { glycérol, mannitol, } \\
\text { sorbitol. }\end{array}$ & $\begin{array}{l}+ \\
(-)\end{array}$ & $\begin{array}{l}\text { Petit nombre de sucres } \\
\text { fermentés. Préférence mar- } \\
\text { quée pour les disacchari- } \\
\text { des, lactose et saccharose. } \\
\text { S. thermophilus est l'un des } \\
\text { streptocoques les moins } \\
\text { "actifs "en ce qui concer- } \\
\text { ne l'éventail des sucres fer- } \\
\text { mentés. }\end{array}$ \\
\hline & $\begin{array}{l}\text { Action sur le lait tour- } \\
\text { nesolé. }\end{array}$ & $\begin{array}{l}\text { Acidification rapide A } \\
\text { Coagulation } \\
\text { Réduction très lente } \\
\text { et souvent incom- } \\
\text { plète du tournesol r }\end{array}$ & $\begin{array}{l}\text { Cette réaction le différen- } \\
\text { cie des autres streptoco- } \\
\text { ques isolés du lait et des } \\
\text { produits laitiers, en parti- } \\
\text { culier des streptocoques } \\
\text { lactiques du groupe séro- } \\
\text { logique } N \text { (RAC). }\end{array}$ \\
\hline
\end{tabular}

* ADN : acide désoxyribonucléique ; G : guanine ; $\mathrm{C}:$ cytosine ; + : réaction positive pour $90 \mathrm{p} .100$ ou plus des souches ; $(-)$ : réaction négative pour 90 p. 100 ou plus des souches; - : réaction toujours négative (d'après Accolas [1]).

\section{TAXONOMIE DES BACTERIES DES LEVAINS LACTIQUES THERMOPHILES}

Les levains lactiques thermophiles contiennent généralement un ou plusieurs lactobacilles (Lactobacillus bulgaricus, L. lactis et $L$. helveticus) et un streptocoque, S. thermophilus.

Les principaux caractères distinctifs de ces bactéries lactiques sont présentés dans les tableaux 1 et 2 tirés d'un article d'Accolas [1]. Du point de vue écologique, ces bactéries sont caractéristiques du lait et de certains produits laitiers et ne sont qu'occasionnellement isolées d'autres biotopes.

S. thermophilus possède un ensemble de propriétés qui individualisent à coup sûr cette espèce. Retenons en particulier l'absence d'antigène de groupe, son caractère thermophile accusé, sa thermorésistance, son activité fermentaire réduite et sa sensibilité au sel. Récemment, Ottogalli et al. [68] ont confirmé le bien-fondé de l'espèce $S$. thermophilus, en étudiant l'homologie des acides désoxyribonucléiques (ADN) extraits de souches représentatives de cette espèce avec des ADN extraits de streptocoques des groupes sérologiques $\mathrm{N}$ ou $\mathrm{D}$, par la technique d'hybridation. En outre, Hemme et Nardi [45] ont obtenu, 
TABLEAU 2

Principaux caractères de $L$. bulgaricus, $L$. lactis et de $L$. helveticus*

\begin{tabular}{|c|c|c|c|c|}
\hline & Caractères & L. bulgaricus & L. lactis & L. helveticus \\
\hline 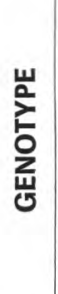 & $\begin{array}{l}\text { Contenu de l'ADN en } G+C \text {. } \\
\text { Homologie des acides nucléi- } \\
\text { ques. } \\
\text { Parenté d'enzymes isofonc- } \\
\text { tionnelles (lacticodéshydrogé- } \\
\text { nases) de différentes souches. }\end{array}$ & $\begin{array}{l}\text { Voisin de } 50 \mathrm{p} .100 . \\
\text { Avec ceux de : } \\
\text { L. lactis : } \geqslant 80 \mathrm{p} .100 . \\
\text { L. helveticus : } 0 \text { à } 40 \mathrm{p} .100 . \\
\text { Avec celles de : } \\
\text { L. lactis: oui. } \\
\text { L. helveticus : non. }\end{array}$ & $\begin{array}{l}\text { Voisin de } 50 \text { p. } 100 \\
\text { Avec ceux de : } \\
\text { L. bulgaricus : } \geqslant 80 \text { p. } 100 \text {. } \\
\text { L. helveticus : } 0 \text { à } 40 \text { p. } 100 . \\
\text { Avec celles de : } \\
\text { L. bulgaricus : oui. } \\
\text { L. helveticus : non. }\end{array}$ & $\begin{array}{l}\text { Voisin de } 39 \mathrm{p} .100 . \\
\text { Avec ceux de : } \\
\text { L. lactis : } 0 \text { à } 40 \text { p. } 100 . \\
\text { L. bulgaricus : } 0 \text { à } 40 \text { p. } 100 . \\
\text { Avec celles de : } \\
\text { L. lactis : non. } \\
\text { L. bulgaricus : non. }\end{array}$ \\
\hline & Morphologie. & $\begin{array}{l}\text { Variable avec l'âge, le milieu, } \\
\text { la souche. Granules métachro- } \\
\text { matiques abondants dans les } \\
\text { cellules de cultures âgées co- } \\
\text { lorées au bleu de méthylène. }\end{array}$ & Comme L. bulgaricus. & $\begin{array}{l}\text { Polymorphisme des cultures } \\
\text { âgées moins accusé que chez } \\
\text { L. lactis et } L \text {. bulgaricus. } \\
\text { Pas de granulations. }\end{array}$ \\
\hline & & $\mathrm{D}(-)$ & D (一) & DL \\
\hline & $\begin{array}{l}\text { Groupe sérologique. } \\
\text { Exigences nutritionnelles : } \\
\text { - riboflavine, } \\
\text { - vitamine B 12, } \\
\text { - pyridoxal, } \\
\text { - acide folique, } \\
\text { - thymidine. }\end{array}$ & $\begin{array}{l}+ \\
- \\
-\end{array}$ & $\begin{array}{l}+ \\
\pm \\
= \\
-\end{array}$ & $\begin{array}{l}\frac{+}{+} \\
\frac{+}{-}\end{array}$ \\
\hline
\end{tabular}


uㅡㅁ Production de gaz à partir

$\sum^{2}$ du glucose.

Température de croissance :

- à $15^{\circ} \mathrm{C}$,

- à $45^{\circ} \mathrm{C}$.

Hydrolyse de l'arginine.

Acide lactique produit dans le lait.

Sucres fermentés :

- fructose,

- galactose,

- glucose,

- lactose,

- maltose,

- mannose,

- saccharose

- tréhalose.

Généralement $\leqslant 1,8$ p. 100.

+
+
+
+
-
-
-
Généralement $\leqslant 1,8$ p. 100 .

Généralement 2 à 2,5 p. 100 .

+
+
+
+
+
+
+
+

ADN : acide désoxyribonucléique; $\mathrm{G}$ : guanine; $\mathrm{C}$ : cytosine; + : réaction positive pour $90 \mathrm{p} .100$ ou plus des souches \pm : réaction variable, lente ou faible ; $(-)$ certaines souches de L. lactis désaminent l'arginine ; - : réaction toujours négative ; (d'après Accolas [1]). 
pour dix souches de $S$. thermophilus, des profils électrophorétiques similaires, à la fois pour les protéines solubles, les $\beta$-galactosidases et les aldolases extraites de chacune de ces souches. Notons toutefois que Lawrence et Thomas [56] estiment que S. thermophilus et de nombreux autres streptocoques, en particulier les streptocoques lactiques mésophiles du groupe sérologique $\mathrm{N}$, pourraient constituer un phylum quasi continu de variants en raison de la similitude de la composition en bases (GC p. 100 de leurs ADN (Knittel [50]). Le caractère thermophile de ce streptocoque suggérerait, selon Law et Sharpe [54], une origine intestinale.

$L$. helveticus et son biotype maltose négatif $L$. jugurti qui a disparu de la dernière classification en date (Rogosa [78]), constitue une espèce dont le génotype se différencie nettement de celui du groupe auquel appartiennent $L$. bulgaricus et $L$. lactis. Cependant, la distinction phénotypique de certaines de ces espèces demeure assez délicate et elle a été jusqu'à un passé récent, en dépit de la classification solidement établie par Orla-Jensen au début du siècle, à l'origine de nombreuses confusions. Cela dit, Dellaglio et al. [26], s'appuyant à la fois sur l'étude du phénotype et sur celle du génotype, ont mis en évidence quelques souches "inclassables " dont la position taxonomique est encore actuellement incertaine.

\section{COMPOSITION DES LEVAINS LACTIQUES THERMOPHILES}

On peut distinguer schématiquement deux types de levains lactiques thermophiles:

\section{- Les levains artisanaux dont la composition est variable et mal connue}

Les petites fromageries du Jura et des Alpes qui fabriquent le gruyère et l'emmental utilisent encore fréquemment des " présures artisanales ». Ce sont des macérations de caillettes de veau préalablement séchées à l'air, dans du lactosérum prélevé chaque jour dans la cuve de fromagerie au terme de la fabrication et utilisé tel quel ou désalbuminé par chauffage et acidification. Ces macérations, incubées de préférence à température relativement élevée $\left(40-45^{\circ} \mathrm{C}\right)$ constituent pour le fromager une source d'enzyme coagulante extraite des caillettes et un levain contenant la flore lactique thermophile indispensable à la réussite du fromage (Accolas et Auclair [2]), Valles et Mocquot [98]). La flore lactique de ces préparations artisanales n'est ni sélectionnée, ni normalisée, et elle est fréquemment composée de plusieurs espèces de lactobacilles ( $L$. fermentum, L. helveticus, L. lactis et, à un moindre degré, $L$. bulgaricus et $L$. acidophilus) et de streptocoques ( $S$. thermophilus et parfois des streptocoques fécaux). 
Les « cultures naturelles » sur lactosérum ( colture naturale in siero ») que préparent et utilisent les fromagers italiens pour fabriquer divers types de fromages, en particulier le grana, appartiennent à la même catégorie de levain. Ces cultures naturelles sont en général très acides et contiennent surtout des lactobacilles appartenant aux mêmes espèces que celles citées précédemment (Bottazzi et al. [14], Carini et Lodi [22]). Notons enfin qu'en Suisse, la Station Fédérale de Recherches Laitières (S.F.R.L.) de Berne travaille en étroite collaboration avec les fromageries suisses d'emmental et leur distribue des cultures mixtes contenant plusieurs souches de $S$. thermophilus et de lactobacilles. Ces cultures mixtes sont aussi des cultures naturelles ( Rohmischkulturen») provenant des meilleures fromageries suisses d'emmental. Elles sont conservées à la S.F.R.L. sous forme lyophilisée de façon à préserver la composition initiale du mélange de souches et elles sont l'objet d'un tri rigoureux, préalable à toute utilisation, qui s'appuie en particulier sur des essais de fabrication réalisés à la fromagerie expérimentale de la Station. En outre, la S.F.R.L., par l'entremise d'un corps d'inspecteurs de fromagerie et d'un service d'analyses de routine, surveille très régulièrement le comportement de ces levains lactiques naturels (Steffen [92]) : déroulement de l'acidification, recherche éventuelle des phages, notation de la qualité des fromages. Si des difficultés surviennent dans une fromagerie, le levain est aussi rapidement que possible modifié en conséquence.

La diversité de la flore bactérienne présente dans ces levains empiriques et leur propagation non aseptique les rendent certainement beaucoup moins sensibles aux attaques de bactériophages que les levains sélectionnés préparés avec un petit nombre de cultures pures. Toutefois, la composition des levains naturels est délicate à maîtriser et sujette à des modifications imprévisibles ; l'activité acidifiante de ces levains peut, en conséquence, subir des variations aléatoires. En outre, une dominance trop marquée des lactobacilles hétérofermentaires (L. fermentum) peut être à l'origine d'une fermentation gazeuse indésirable dans le jeune fromage et de l'apparition de défauts d'ouverture qui déprécient gravement le fromage affiné. Pour éviter ces aléas, Bottazzi et al. [15] ont décrit une série d'épreuves de contrôle et ont fixé des normes permettant d'apprécier la composition approximative et la qualité des levains naturels italiens.

\section{- Les levains sélectionnés de composition connue}

On a aussi recours à des levains sélectionnés contenant une ou plusieurs souches de $S$. thermophilus et de lactobacilles (L. bulgaricus, L. lactis, L. helveticus) surtout dans la fabrication industrielle des fromages à pâte cuite. Dans le cas du yoghourt, le levain est presque toujours exclusivement composé d'une ou deux souches de chacune des deux espèces $S$. thermophilus et L. bulgaricus (Accolas [1]). Les laiteries disposent de leur propre collection de souches ou s'approvisionnent auprès de fournisseurs spécialisés. Des associations sélec- 
tionnées et (ou) des rotations de souches, s'appuyant sur une connaissance des relations phagiques de ces souches, ne sont pas employées d'une manière aussi systématique que dans le cas des levains lactiques mésophiles utilisés dans les pays anglo-saxons.

\section{UTILISATION DE LEVAINS LACTIQUES THERMOPHILES CONCENTRES}

Les suspensions concentrées de bactéries lactiques sont couramment utilisées à l'heure actuelle par de nombreuses usines laitières, pour ensemencer le levain proprement dit, première étape qui simplifie déjà la tâche des laiteries. Dès 1968, le travail de Rousseaux et al. [79] mettait clairement en évidence les possibilités offertes par les concentrés congelés de bactéries lactiques thermophiles, pour l'ensemencement direct du lait de fabrication, en fromagerie de pâtes cuites. Comme le montre à titre d'exemple la figure 1, il est en effet possible de conserver à température moyennement basse $\left(-30^{\circ} \mathrm{C}\right)$ des concentrés de $L$. helveticus sans observer de diminution de la survie ni de l'activité acidifiante, pendant de longues périodes. La technique d'ensemencement direct présente en outre un intérêt tout particulier dans le cas du gruyère et de l'emmental parce que la quantité de ferments employés est dix à trente fois moindre que celle qui est requise dans d'autres fabrications fromagères ou dans le cas du yoghourt.

Il est loisible de penser que l'emploi de concentrés de bactéries lactiques thermophiles, comme celui des concentrés de bactéries lactiques mésophiles, se développera de façon irréversible dans l'avenir et s'appliquera couramment à l'ensemencement direct du lait. A l'appui de cette affirmation, le tableau 3 où sont rassemblés à titre d'exemple des résultats obtenus à l'échelle pilote par l'un de nous, montre que les concentrés congelés de bactéries lactiques thermophiles sont d'une qualité moyenne satisfaisante. Ajoutons que l'expérimentation en technologie laitière (fabrication de fromages à pâte cuite ou de yoghourts) a amplement confirmé cette qualité.

Il y a quelques années, un travail de Speckman [85] et une brève communication de Porubcan et Sellers [74] suggéraient que des préparations lyophilisées ou séchées de bactéries du yoghourt pourraient rapidement se substituer aux concentrés congelés. Ce type de préparations présente en effet d'indéniables avantages sur les concentrés congelés, pour le transport et la conservation. Toutefois, les résultats de ces auteurs ne sont pas pleinement convaincants et l'expérience acquise dans notre laboratoire montre que les concentrés de bactéries lactiques thermophiles ne se prêtent pas aussi aisément à la lyophilisation qu'à la congélation (cf. tab. 3). Au mieux, dans le cas de $S$. thermophilus, les nombres de germes vivants et les activités acidifiantes se 

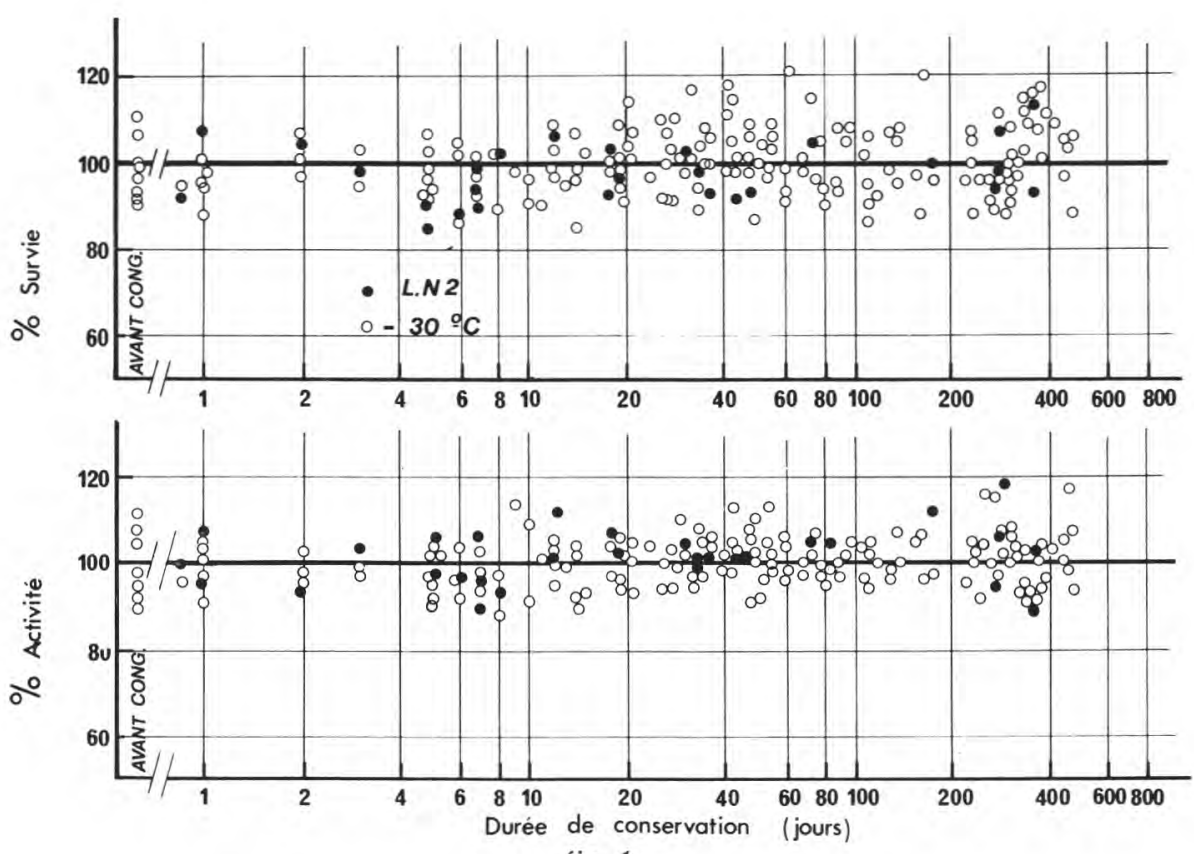

fig. 1

Conservation à l'état congelé de sept suspensions concentrées de Lactobacillus helveticus

Avant cong. :

LN 2 :

Survie \% :

Activité acidifiante \%: expression des résultats expérimentaux en unités d'activité selon la méthode d'Accolas et AucLaIr [3]. La valeur 100 , pour chacune des suspensions, est la moyenne des résultats obtenus tout au long de la conservation.

(Données inédites de J.P. Accolas).

maintiennent en moyenne à un niveau comparable à ceux des concentrés congelés. En d'autres termes, la lyophilisation affecte les cellules de ces streptocoques thermophiles à un point tel que l'effet de concentration est masqué, alors qu'il apparaissait encore nettement dans le 


\section{TABLEAU 3}

Comparaison de suspensions concentrées congelées et de suspensions concentrées lyophilisées de bactéries lactiques thermophiles*

\begin{tabular}{|c|c|c|c|c|}
\hline $\begin{array}{c}\text { Espèce } \\
\text { et nombre } \\
\text { de } \\
\text { souches }\end{array}$ & 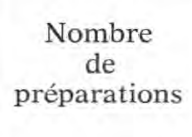 & $\begin{array}{l}\text { Rend. pondéral } \\
\text { moyen } \\
\text { (kg p. } 1001 \text { de } \\
\text { culture) }\end{array}$ & $\begin{array}{l}\text { Nombre moyen } \\
\text { de germes } \\
\text { par } \mathrm{g} \\
\text { (x 1010) }\end{array}$ & $\begin{array}{l}\text { Activité } \\
\text { acidifiante } \\
\text { moyenne } \\
\text { (unités par g) }\end{array}$ \\
\hline $\begin{array}{l}\text { S. thermophilus } \\
\text { (3 souches) }\end{array}$ & $\begin{array}{l}15 \mathrm{SC} \\
14 \mathrm{SL}\end{array}$ & $\begin{array}{l}1,96 \\
0,71\end{array}$ & $\begin{array}{l}19,5 \\
14\end{array}$ & $\begin{array}{l}625 \text { UST } \\
600 \text { UST }\end{array}$ \\
\hline $\begin{array}{l}\text { L. helveticus } \\
\text { (1 souche) }\end{array}$ & $\begin{array}{l}13 \mathrm{SC} \\
11 \mathrm{SL}\end{array}$ & $\begin{array}{l}2,44 \\
0,23\end{array}$ & $\begin{array}{l}11 \\
2,9\end{array}$ & $\begin{array}{l}166 \text { ULH } \\
176 \text { ULH }\end{array}$ \\
\hline $\begin{array}{l}\text { L. bulgaricus } \\
\text { (4 souches) }\end{array}$ & $\begin{array}{l}8 \mathrm{SC} \\
5 \mathrm{SL}\end{array}$ & $\begin{array}{l}1,97 \\
0,75\end{array}$ & $\begin{array}{l}6,9 \\
0,02\end{array}$ & $\begin{array}{l}106 \text { ULB } \\
10 \text { ULB }\end{array}$ \\
\hline \multicolumn{5}{|c|}{$\begin{array}{l}\text { * Données inédites de C. BourllanNe: } \mathrm{SC}=\text { suspension congelée et } \mathrm{SL}=\text { suspension } \\
\text { lyophilisée. La préparation des suspensions était effectuée comme il est indi- } \\
\text { qué dans BouILLANNE et al. [16]. Les dénombrements étaient effectués sur } \\
\text { gélose M } 17 \text { [95] dans le cas de S. thermophilus et sur gélose MRS (Difco) dans } \\
\text { le cas des lactobacilles. L'activité acidifiante était exprimée suivant un système } \\
\text { d'unités propre à chaque espèce (UST, ULH ou ULB), selon la méthode } \\
\text { d'Accolas et AUCLAIR [3]. }\end{array}$} \\
\hline
\end{tabular}

cas des concentrés lyophilisés de streptocoques lactiques mésophiles (Bouillanne et al. [16], Bouillanne et Auclair [17]. Dans le cas de $L$. helveticus, les activités acidifiantes des concentrés lyophilisés sont également du même ordre que celles des concentrés congelés, alors que la survie moyenne après lyophilisation chute nettement ; cela laisse penser que les dénombrements sur gélose (survie) constituent un révélateur plus "sévère " des dommages subis par les cellules lyophilisées que l'activité acidifiante. Au pire enfin, L. bulgaricus se prête très mal à la lyophilisation et les résultats moyens obtenus avec ce germe sont particulièrement décevants et médiocres. La " fragilité » de $L$. bulgaricus a été mise en évidence en diverses occasions, par exemple dans le cas de la congélation simple lorsque ce lactobacille n'est pas cultivé au préalable sur un milieu ad hoc (Smittle et al. [83]), ou encore dans le cas de la lyophilisation lorsque tout un ensemble de conditions optimales (état physiologique des cellules, milieu protecteur, mode de lyophilisation, atmosphère de conservation, mode de réhydratation, etc.) ne sont pas réunies (Morichi [64]). Les suspensions mixtes, associant $S$. thermophilus à l'un des lactobacilles précédents, ne modifient pas de façon notable le comportement de chacun des deux 
germes. Ainsi les concentrés lyophilisés mixtes contenant à la fois $S$. thermophilus et $L$. bulgaricus sont complètement déséquilibrés à l'avantage du streptocoque.

Bien entendu, les résultats moyens rapportés ci-dessus ne donnent qu'un bilan global. Cela sous-entend que, dans les meilleurs cas, pour l'un ou l'autre type de préparation, on peut obtenir des résultats bien supérieurs aux moyennes indiquées. En définitive, cela laisse quelque espoir de progresser encore dans cette voie, en dépit des sérieuses difficultés rencontrées.

\section{A. LE YOGHOURT}

Bon exemple du produit laitier frais de grande consommation dans de nombreux pays d'Europe, en plein essor dans divers pays d'Amérique et au Japon, le yoghourt est maintenant couramment fabriqué dans des ateliers industriels bien équipés et de grande capacité.

La principale préoccupation des industriels est d'obtenir régulièrement un produit de bonne qualité. Cet objectif implique un ajustement judicieux de la qualité du lait mis en œuvre, des propriétés des cultures bactériennes utilisées et de la technique de fabrication. Ces différents facteurs affectent, à des degrés divers, le déroulement de la fermentation.

\section{INFLUENCE DE LA QUALITE DU LAIT}

Les bactéries lactiques thermophiles sont des bactéries exigeantes du point de vue nutritionnel et elles ne trouvent pas toujours dans le lait, sous forme facilement assimilable, les divers composés qui leur sont nécessaires pour que leur croissance et l'acidification soient optimales.

Ainsi a-t-on pu observer des variations très importantes d'un lait à un autre et suivant la saison, la meilleure acidification étant généralement obtenue en été, alors que, dans un lait témoin, l'acidification se déroulait de façon reproductible d'un essai à l'autre (fig. 2, tirée de Vassal et Auclair [99]). Selon les auteurs, les variations observées pouvaient être attribuées, pour une part, aux modifications subies par le lait en raison du métabolisme de la flore de contamination du lait cru. D'autre part, dans le cas où l'acidification devenait très lente, les laits contenaient de la pénicilline. Il est en effet connu que les bactéries lactiques thermophiles sont très sensibles aux antibiotiques (Cogan [23]). Par exemple, une concentration de pénicilline égale à $0,005 \mathrm{UI} / \mathrm{ml}$ est suffisante pour provoquer un retard notable de l'acidification. 

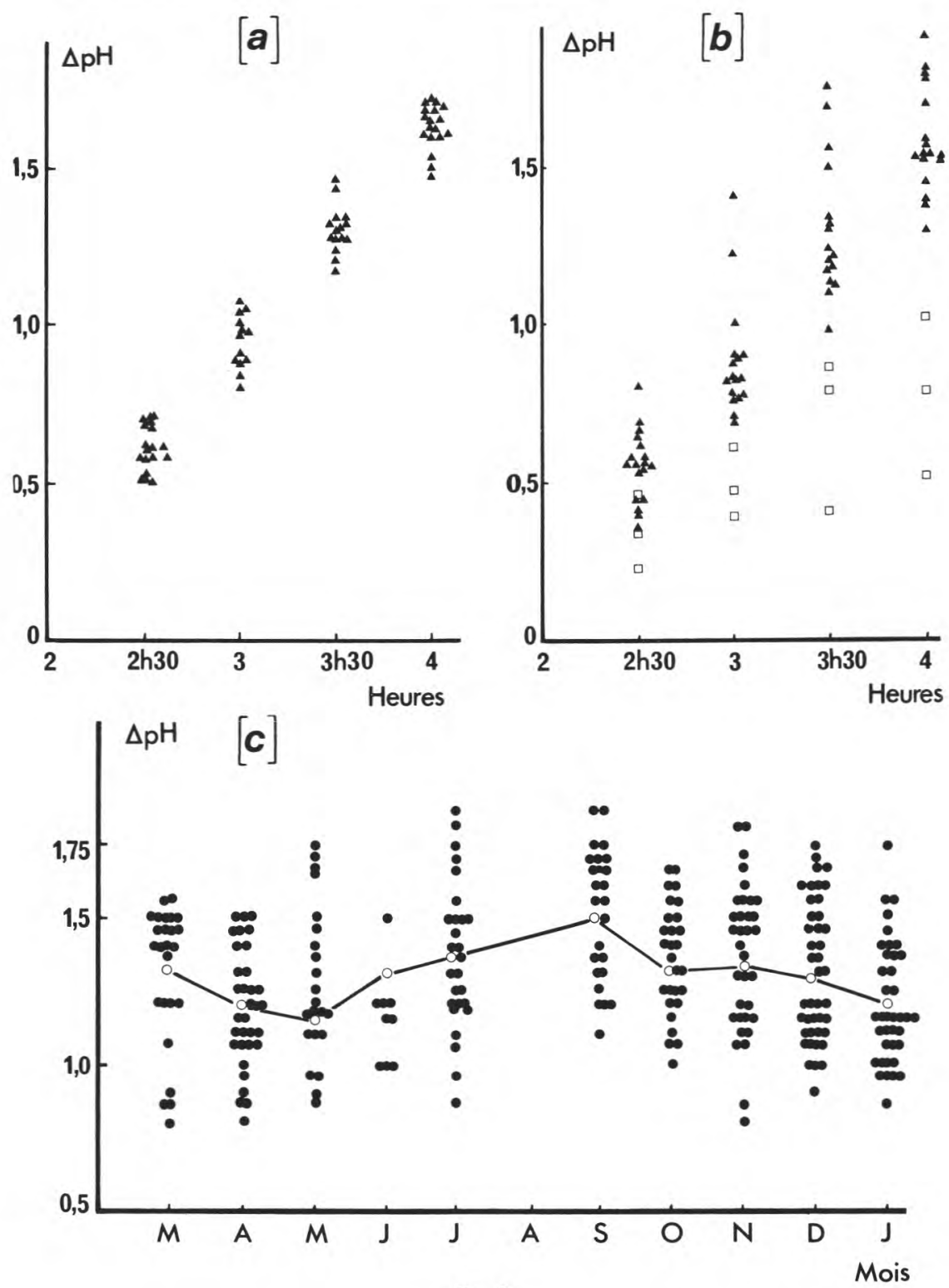

fig. 2

Variations de la production d'acide par les bactéries du yoghourt dans les laits de grand mélange (d'après Vassal et Auclair [99])

a) Différences des valeurs de $\mathrm{pH}(\Delta \mathrm{pH})$ mesurées dans un lait témoin, reconstitué à partir d'une poudre de lait écrémé diluée à $10 \mathrm{p} .100$ et chauffé à $85^{\circ} \mathrm{C}$ pendant $10 \mathrm{~min}$. Inoculum : 1 p. 100 de chacune des deux souches utilisées, $S$. thermophilus et $L$. bulgaricus. Incubation à $45^{\circ} \mathrm{C}$.

b) Différences des valeurs de $\mathrm{pH}(\Delta \mathrm{pH})$ mesurées dans vingt échantillons de lait de grand mélange de deux origines différentes. Les signes $\square$ correspondent à des échantillons de lait contenant de la pénicilline. Chauffage des laits, inoculum et incubation : voir a).

c) Différences entre les valeurs de $\mathrm{pH}(\Delta \mathrm{pH})$ mesurées au début et après $3 \mathrm{~h} 30$ d'incubation dans des échantillons de lait de grand mélange reçus mois par mois. Chauffage des laits, etc. : voir a. Les signes 0 correspondent aux moyennes mensuelles et sont reliés par un trait. 
L'addition de sucre (saccharose) au lait, en particulier dans le cas des yoghourts aux fruits où elle peut atteindre 8 à 10 p. 100 , peut être préjudiciable à la fermentation. Selon Bills et al. [13], le développement des germes et la production d'acide sont affectés à partir de 4 p. 100 de sucre, alors que la production d'acétaldéhyde (considérée comme un composant majeur de l'arôme du yoghourt) ne l'est qu'à partir de 8 p. 100. Selon Tramer [97], l'effet inhibiteur observé dans le lait sucré résulterait plus d'un taux de matière sèche trop élevé (le lait destiné à la fabrication du yoghourt est en effet enrichi en matière sèche, soit par évaporation préalable, soit par addition de lait en poudre, pour améliorer la consistance du produit) dans les yoghourts sucrés que de l'addition de sucre elle-même. Toutefois, il ne semble pas que toutes les cultures utilisées soient également affectées par l'addition de sucre (Gordon et Shapton [42]).

\section{- Le chauffage du lait}

Le traitement thermique du lait destiné à la fabrication du yoghourt est effectué à des températures relativement élevées et pendant des durées relativement longues. De nombreuses combinaisons température-temps sont appliquées en pratique (Robinson et Tamine [77]). Le chauffage préalable du lait a pour objectif d'assurer la qualité hygiénique et la stabilité du produit ; il permet en outre d'obtenir une bonne consistance et de limiter la synérèse du caillé. Mais le traitement thermique a aussi pour effet de favoriser le développement des bactéries du yoghourt et ce faisant, de régulariser la fermentation. Pour une part, on peut attribuer cet effet à la destruction des substances inhibitrices naturelles présentes dans le lait cru (système lactoperoxydase-thiocyanate ; agglutinines) auxquelles $L$. bulgaricus est très sensible (Portmann et al. [73]). Cet effet résulte surtout de l'apparition, dans le lait chauffé à des températures supérieures à $90^{\circ} \mathrm{C}$, de divers composés stimulants pour les bactéries du yoghourt tels que les produits de dégradation de la caséine dans le cas de $S$. thermophilus (Auclair [10], Lorient et al. [59] ou l'acide formique formé à partir du lactose dans le cas L. bulgaricus (Auclair [10]).

\section{PROPRIETES DES BACTERIES DU YOGHOURT}

Les propriétés fermentaires, aromatiques et épaississantes des bactéries lactiques du yoghourt confèrent au produit final ses caractéristiques organoleptiques. Du point de vue fondamental, on doit reconnaître d'emblée que ces propriétés sont encore assez mal connues, alors même que le technologue sait plus ou moins empiriquement les utiliser à bon escient. 


\section{- Fermentation du lactose}

La fermentation du lactose par les bactéries lactiques du yoghourt, $S$. thermophilus et $L$. bulgaricus, s'effectue selon la voie homofermentaire de la glycolyse. Cela dit, on ne dispose pas d'études suffisamment approfondies pour donner un schéma cohérent et précis de l'ensemble de la voie de fermentation. Prenons pour exemple le cas de $S$. thermophilus. Il est connu depuis longtemps que ce streptocoque fermente préférentiellement des disacharides, lactose et saccharose et que de nombreuses souches sont incapables de fermenter le galactose (plus rarement le glucose) qui est excrété et, de ce fait, s'accumule dans le milieu de culture (ou dans le lait). Une étude récente de Somkuti et Steinberg (84) a par exemple montré que 31 souches de $S$. thermophilus se répartissaient en trois groupes. Le premier groupe comprenait 12 souches qui fermentaient lactose, glucose et galactose ; le second, 18 souches qui fermentaient lactose et glucose, et le troisième une souche qui ne fermentait que le lactose. En outre, ces auteurs ont observé un effet inhibiteur sur la croissance, lorsqu'ils ajoutaient du galactose à des souches du second groupe cultivées sur bouillon lactosé. Par contre, Hemme et al. [47] n'ont pas observé d'effet inhibiteur lorsqu'ils ajoutaient du galactose à des cultures sur lait de $S$. thermophilus.

Différents travaux laissaient penser qu'une hydrolyse préalable du lactose du lait en glucose et galactose, exerçait une influence bénéfique sur l'acidification des levains lactiques thermophiles (voir à ce sujet la référence [44]), encore que Tamine [94] ait obtenu des réponses variables avec des cultures mixtes de $L$. bulgaricus et de $S$. thermophilus. En outre, Hemme et al. [44] ont montré que l'hydrolyse du lactose par une $\beta$-galactosidase purifiée était sans action et que l'effet stimulant observé précédemment résultait de l'action d'enzymes protéolytiques présentes dans les préparations commerciales de lactase insuffisamment purifiées.

Si l'on considère maintenant le tableau 4, S. thermophilus paraît posséder à la fois une $\beta$-galactosidase et une phospho- $\beta$-galactosidase. Toutefois les variations concomitantes des deux activités enzymatiques selon les conditions de culture (Hemme et al. [47]), la similitude de la résistance thermique et de la migration électrophorétique (Hemme et Nardi [45]), enfin l'élution identique lors de chromatographies sur gel d'exclusion ou sur résine échangeuse d'ions (Hemme, résultats inédits) conduisent à penser qu'on a affaire à deux isoenzymes possédant chacune les deux activités $\beta$-galactosidase et phospho- $\beta$-galactosidase. Si tel est bien le cas, il s'agirait là d'enzymes d'un type nouveau, caractéristiques de $S$. thermophilus et moins spécifiques que la phospho- $\beta$ galactosidase généralement présente chez les streptocoques lactiques mésophiles.

Revenons au tableau 4. Dans le cas de la souche 302 (assez représentative de l'espèce en ce que son développement et son pouvoir acidifiant sont rapidement affectés par les bas $\mathrm{pH}$ ) on observe une 


\section{TABLEAU 4}

Variations des activités spécifiques des enzymes de la glycolyse, chez Streptococcus thermophilus, selon la souche et selon le $\mathrm{pH}$ de la culture*

\begin{tabular}{|c|c|c|c|c|c|c|}
\hline \multirow{3}{*}{ Enzymes de la glycolyse } & \multirow{2}{*}{\multicolumn{2}{|c|}{$\begin{array}{l}\text { Activités } \\
\text { spécifiques } \\
\text { à pH } 6,32\end{array}$}} & \multicolumn{4}{|c|}{$\begin{array}{c}\text { Variations des activités } \\
\text { en fonction du pH de la } \\
\text { culture } \\
(100 \text { p. } 100=\text { activité } \\
\text { à pH } 6,32)\end{array}$} \\
\hline & & & \multicolumn{2}{|c|}{ pH 5,62} & \multicolumn{2}{|c|}{$\mathrm{pH} 5,10$} \\
\hline & 302 & 385 & 302 & 385 & 302 & 385 \\
\hline$\beta$-galactosidase & 3,3 & 3,8 & 171 & 108 & 338 & 143 \\
\hline Phospho- $\beta$-galactosidase & 3,9 & 5,7 & 148 & 147 & 452 & 167 \\
\hline Hexokinase & 1,4 & 1,1 & 103 & 143 & 60 & 179 \\
\hline Aldolase & 2,9 & 28,4 & 163 & 102 & 155 & 108 \\
\hline Glycéraldéhyde-3-phosphate déshydrogénase & 3,1 & 9,8 & 173 & 130 & 205 & 162 \\
\hline Pyruvate kinase & 1,3 & 1,4 & 135 & 129 & 205 & 136 \\
\hline L-lacticodéshydrogénase & 21,3 & 16,9 & 95 & 98 & 112 & 135 \\
\hline \multicolumn{7}{|c|}{$\begin{array}{l}\text { * Moyennes de trois essais indépendants. } S \text {. thermophilus } 302 \text { et } 385 \text { étaient culti- } \\
\text { vés dans du milieu M } 17 \text { à } 42^{\circ} \mathrm{C} \text { (concentration en lactose : } 10 \mathrm{~g} / 1 \text { ). Lorsque } \\
\text { les cultures atteignaient le pH désiré, elles étaient rapidement refroidies à } \\
0^{\circ} \mathrm{C} \text {; les bactéries étaient aussitôt récoltées et broyées. Les activités des } \\
\text { extraits bruts étaient mesurées et rapportées à } 1 \mathrm{mg} \text { de protéines. Les activités } \\
\beta \text {-gal et P- } \beta \text {-gal étaient déterminées respectivement par l'hydrolyse de l'ONPG } \\
\text { et de l'ONPG-6-P. (Activités spécifiques à pH } 6,32: \text { données inédites de } \\
\text { D. HemME ; variations des activités en fonction du pH : d'après Hemme et } \\
\text { al. [47]). }\end{array}$} \\
\hline
\end{tabular}

augmentation notable de l'activité intracellulaire des enzymes glycolytiques lorsque le $\mathrm{pH}$ baisse, à l'exception de l'hexokinase ; l'activité réduite de cette enzyme à bas $\mathrm{pH}$ pourrait ralentir la poursuite de la glycolyse. Par contre, la souche 385 qui présente un pouvoir acidifiant très supérieur à celui de la plupart des autres $S$. thermophilus, possède des enzymes glycolytiques apparemment moins sensibles aux bas $\mathrm{pH}$. En outre, l'aldolase de cette souche présente une activité environ dix fois plus élevée que celle des autres $S$. thermophilus, ce qui pourrait expliquer le comportement très particulier de cette souche (Accolas et al. [5]). 
Ces résultats laissent penser qu'une étude approfondie de la voie fermentaire chez ces bactéries lactiques thermophiles pourrait utilement compléter les données (nombreuses mais encore insuffisantes) acquises dans le cas des streptocoques lactiques mésophiles (Lawrence et Thomas [56]).

\section{- Production d'arôme}

On attribue classiquement un rôle de premier plan à l'acétaldéhyde dans la formation de l'arôme du yoghourt (Dumont et Adda [36]), encore qu'un certain nombre d'autres produits aromatiques figurent parmi les nombreux composés volatils que révèlent les techniques d'analyse fine (Dumont et Adda [35]) et contribuent certainement à l'arôme subtil d'un bon yoghourt. Un rapport acétaldéhyde/acétone voisin de 2,8 est par exemple considéré comme optimal (Mocquot et Hurel [63]). La production d'acétaldéhyde est avant tout le fait de $L$. bulgaricus. A première vue, on pourrait penser que l'acétaldéhyde est formée à partir du pyruvate par décarboxylation, comme c'est le cas chez de nombreux streptocoques lactiques mésophiles, en particulier chez ceux qui fermentent le citrate du lait. Il est toutefois vraisemblable que, dans le cas des bactéries du yoghourt, le pyruvate formé à partir du lactose est affecté en totalité à la production d'acide lactique afin de permettre au cycle de la glycolyse de se poursuivre. Selon Lees et Jago [57], L. bulgaricus possède une thréonine aldolase qui cliverait cet acide aminé en acétaldéhyde et en glycine. Cela est conforme à l'observation de Veringa [102], qui a montré que l'addition de thréonine au lait active notablement la production d'acétaldéhyde du yoghourt. Notons aussi que l'accumulation de l'acétaldéhyde dans le yoghourt indique que les bactéries du yoghourt, à la différence des streptocoques mésophiles, ne disposent pas des déshydrogénases nécessaires pour dégrader l'acétaldéhyde.

\section{- Synergie des bactéries du yoghourt}

Pour clore cette revue des propriétés des bactéries du yoghourt, il convient de mentionner que $L$. bulgaricus et $S$. thermophilus cultivés en association dans du lait représentent, dans de nombreux cas, un bon exemple de métabolisme intégré où chaque espèce tire bénéfice de la culture mixte. Comme le montre la figure 3 , la production d'acide et la production d'acétaldéhyde de la culture mixte sont beaucoup plus actives que celles des cultures pures (Accolas et al. [5], Hamdan et al. [43]). On peut également observer un effet synergique marqué sur la consistance et la viscosité du produit lorsqu'on emploie des cultures épaississantes (Galesloot et Hassing $[40,41]$ ). Enfin, la synergie des bactéries du yoghourt expliquerait aussi, pour une bonne part, la remarquable stabilité des cultures mixtes dans le cas de la fabrication continue du yoghourt (Driessen et al. [32], Macbean et al. [60]). 

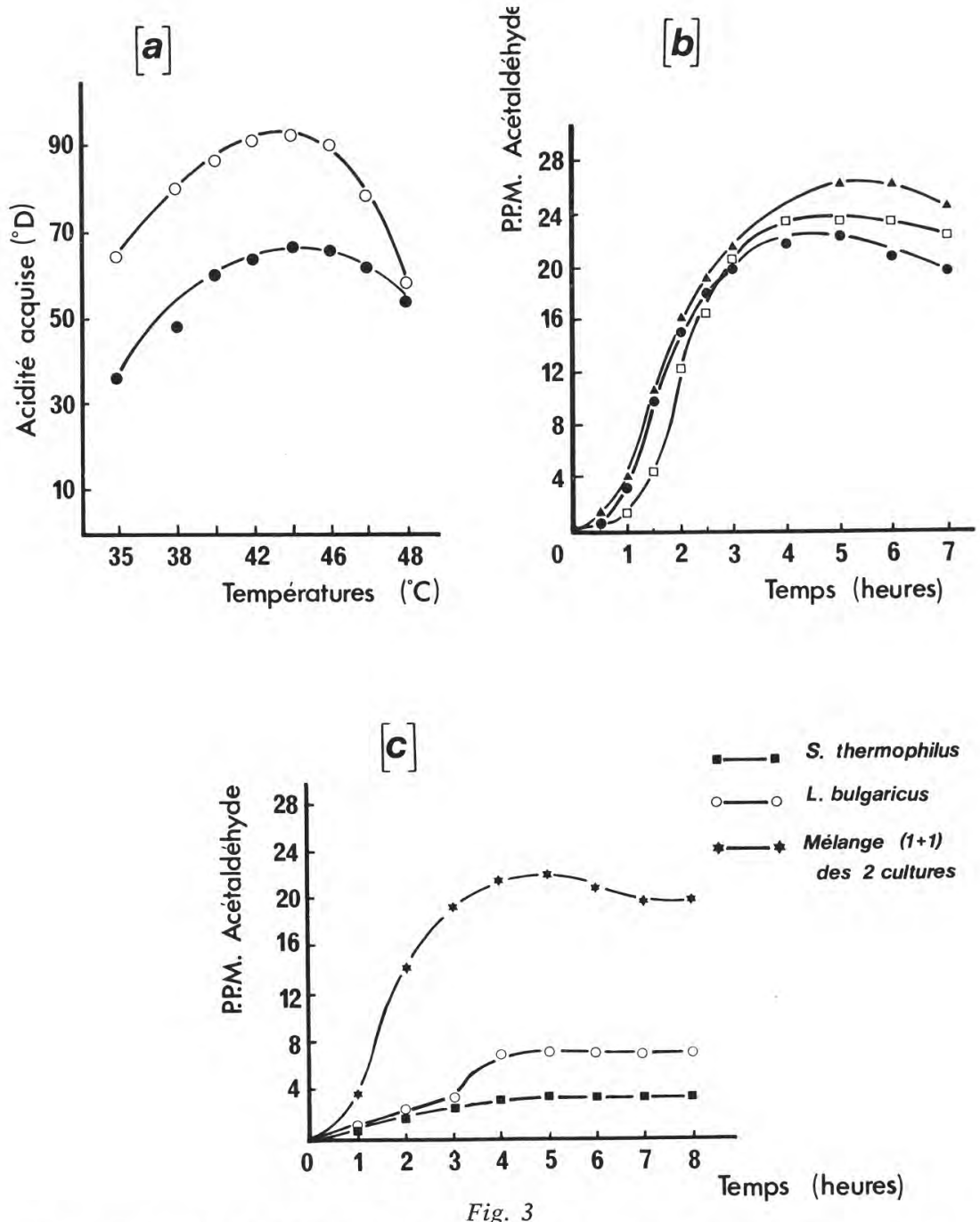

Productions d'acétaldéhyde et d'acide lactique par les bactéries du yoghourt.

Effets synergiques de la culture mixte

a) Productions d'acide comparées de cultures mixtes de $S$. thermophilus et de $L$. bulgaricus et des cultures pures correspondantes, à différentes températures. Inoculum : 1 p. 100 pour les cultures pures et 0,5 p. 100 de chaque souche pour les cultures mixtes ; l'acidité acquise, exprimée en degrés Dornic, a été calculée en déduisant chaque fois l'acidité naturelle du lait (d'après Accolas et al. [5]).

- - : somme moyenne des acidités produites par les cultures pures de $L$. bulgaricus (une souche) et de $S$. thermophilus (trois souches). ०-० : acidité moyenne produite par les trois cultures mixtes correspondantes.

b) Production d'acétaldéhyde par trois cultures mixtes dans du lait entier additionné de $3 \mathrm{p} .100$ de poudre de lait écrémé et autoclavé à $116^{\circ} \mathrm{C}$ pendant 10 min. Inoculum : 3 p. 100 de culture ; incubation à $45^{\circ} \mathrm{C}$ (d'après HaMdaN et al. [43]).

c) Production d'acétaldéhyde par S. thermophilus, par L. bulgaricus et par la culture mixte (mélange $1+1$ ) des deux souches. Conditions de culture : voir b (đaprès HaMdan et al. [43]). 
Il est maintenant bien établi que divers lactobacilles thermophiles, en particulier $L$. bulgaricus, exercent un effet stimulant marqué sur le développement et la production d'acide de $S$. thermophilus. Au cours des 3 dernières décennies, les connaissances acquises dans ce domaine se sont notablement étoffées grâce à des travaux poursuivis dans trois directions.

En premier lieu, Pette et Lolkema [70] attribuèrent, dès 1950, l'effet stimulant observé à l'action protéolytique du lactobacille et le bien-fondé de leur hypothèse a été confirmé par des travaux ultérieurs (Bautista et al. [12], Higashio et al. [48], Shankar et Davies [81, 82]). En outre, il a été montré que $L$. bulgaricus possède différentes endopeptidases et exopeptidases dont l'action globale sur les caséines ou sur le lait a été étudié par Miller et Kandler [61], Tourneur [96] et El Soda [37]. De même, Argyle et al. [9] ont mis en évidence, chez ce lactobacille, une endopeptidase liée à la paroi cellulaire dont l'activité optimale se situait à $\mathrm{pH} 5,8$ et à $47,5^{\circ} \mathrm{C}$. Notons aussi qu'il n'est pas possible, en ajoutant au lait des broyats cellulaires de souches de L. bulgaricus, d'obtenir un effet stimulant sur $S$. thermophilus comparable à celui qu'on observe dans du lait où sont cultivées ces mêmes souches de L. bulgaricus, c'est-à-dire du lait soumis à l'action des cellules entières de ce lactobacille (Hemme et al. [46]).

En second lieu, il a été montré que l'addition au lait de certaines combinaisons minimales d'acides aminés (un mélange contenant tous les acides aminés engendre généralement une action très favorable au développement de $S$. thermophilus) exerçait un effet stimulant notable sur ce streptocoque thermophile (cf. tab. 5). La diversité des résultats obtenus par différents auteurs peut provenir à la fois de la composition du lait utilisé, du traitement thermique appliqué à ce lait et enfin des souches étudiées. De plus, il n'est pas certain qu'on reproduise fidèlement l'effet synergique observé dans une culture mixte lorsqu'on cherche à mettre en évidence, par analogie, l'effet stimulant de certaines combinaisons d'acides aminés.

En troisième lieu, l'action stimulante observée sur la production d'acide de $S$. thermophilus peut tout aussi bien résulter de la présence de peptides (Bracquart et Lorient [21], Desmazeaud et Devoyod [28], Lorient et al. [59], Shankar et Davies [81, 82]). Les travaux de Desmazeaud et al. constituent, à divers titres, une contribution déterminante dans ce domaine. Il a en effet été montré que $S$. thermophilus est doté d'endo et d'exopeptidases intracellulaires de spécificité générale qui lui permettent d'utiliser les peptides exogènes comme source d'azote [31]. S. thermophilus CNRZ 160, par exemple, possède une endopeptidase intracellulaire qui présente les propriétés générales et la spécificité d'action caractéristiques des métalloprotéases neutres (EC 3.4.24.4.) [27], ainsi qu'une aminopeptidase et une dipeptidase intracellulaires ayant une large spécificité [75]. Autrement dit, $S$. thermophilus est équipé de peptide-hydrolases intracellulaires qui lui permettent d'utiliser les peptides exogènes soit comme une source 


\section{TABLEAU 5}

Effets stimulants de l'addition d'acides aminés sur la production d'acide de $S$. thermophilus dans du lait

\begin{tabular}{|c|c|c|}
\hline $\begin{array}{l}\text { Nombre de } \\
\text { souches étudiées }\end{array}$ & Acides aminés stimulants & Références \\
\hline 1 & $\begin{array}{l}\text { Mélange de six à onze acides } \\
\text { aminés, suivant la saison. Val } \\
\text { très active. }\end{array}$ & Pette et Lolkema, 1950 [70]. \\
\hline $6\left\{\begin{array}{l}1 \\
5\end{array}\right.$ & $\begin{array}{l}\text { His ou His + Gly. } \\
\text { His. }\end{array}$ & Bautista et al., 1966 [12]. \\
\hline $4\left\{\begin{array}{l}1 \\
3\end{array}\right.$ & $\begin{array}{l}\text { Leu + Ile + Val. } \\
\text { Leu + His + Val. }\end{array}$ & Accolas et al., 1971 [4]. \\
\hline 1 & $\begin{array}{l}\text { Glu, Met, Phe, His, Arg ; mé- } \\
\text { lange Glu + His + Met très } \\
\text { actif. }\end{array}$ & BRACQUART et LORIENT, 1977 [19] \\
\hline 5 & Glu + His + Met. & BRACQUART et al., 1978 [20]. \\
\hline 6 & $\mathrm{Glu}+\mathrm{His}+\mathrm{Met}+\mathrm{Leu}+$ Val. & HigaSHIO et al., 1978 [48]. \\
\hline Non précisé & $\begin{array}{l}\text { Glu + His + Met + Leu + Val } \\
+ \text { Trp. }\end{array}$ & SHANKaR et DaviEs, 1978 [82]. \\
\hline
\end{tabular}

générale d'acides aminés [29, 30], soit comme une source préférentielle d'histidine lorsque cet acide aminé se trouve en position $\mathrm{NH}_{2}$-terminale dans la chaîne peptidique [30.]. Dans ce dernier cas, il existe un " effet de taille » du peptide qui fait que l'action stimulante observée diminue lorsque le nombre de résidus d'acides aminés passe de 5 à 12 ; en outre, les peptides de poids moléculaire élevé sont sans action. Enfin, des di ou des tripeptides tels que His-Ser, Lys-Tyr-Leu et AspSer-Arg déterminent un effet inhibiteur.

D'autre part, Galesloot et al. [39] et Veringa et al. [101] ont montré que $S$. thermophilus exerçait un effet stimulant notable sur L. bulgaricus, effet qui est lié à la production d'acide formique. Cet effet stimulant a été observé par d'autres auteurs (Accolas et al. [4], Shankar et Davies [82]) tandis que Higashio et al. [48] ont mis en évidence un effet cumulatif de l'acide formique et de l'acide pyruvique.

On dispose donc, à l'heure actuelle, de tout un ensemble de données solides sur les facteurs responsables de la synergie qui se mani- 
feste lorsque $S$. thermophilus et $L$. bulgaricus sont cultivés ensemble dans du lait. Notons en outre que cette synergie est sans doute responsable de la stabilité de nombreuses cultures mixtes de yoghourt et de leur production d'acide rapide et régulière [5], ce dont les fabricants de yoghourt tirent le plus grand profit, en pratique.

\section{FERMENTATION LACTIQUE CONTINUE APPLIQUEE A LA FABRICATION DU YOGHOURT}

La fermentation continue a été utilisée industriellement pour fabriquer des yoghourts. Sous sa forme la plus simple (Auclair et Mocquot [11], Lelieveld [58]) elle comporte une cuve de préfermentation où le $\mathrm{pH}$ du lait est maintenu constant à une valeur voisine de 5,7 par addition continue de lait non fermenté, tandis que le lait fermenté est soutiré et réparti en pots et l'incubation terminée dans des chambres étuves (yoghourt ferme) ou envoyé dans une seconde cuve où l'acidification est menée à son terme (yoghourt brassé). Le choix d'un $\mathrm{pH}$ de fermentation relativement élevé est destiné à éviter la coagulation prématurée du lait, qui nuirait à la bonne homogénéité de la fermentation. La coagulation acide du lait commence en effet à un $\mathrm{pH}$ voisin de 5,5 aux températures d'incubation utilisées dans la fabrication du yoghourt $\left(40-45^{\circ} \mathrm{C}\right)$.

Le procédé de fermentation continue du yoghourt à $\mathrm{pH}$ constant a fait récemment l'objet d'études théoriques et de vérifications expérimentales (Driessen et al. [32], Macbean et al. [60]), qui ont confirmé la remarquable stabilité de l'association des deux bactéries du yoghourt en culture continue. Macbean et al. se sont en outre livrés à une analyse critique détaillée des facteurs responsables du comportement de l'association bactérienne en culture continue.

D'autre part, Driessen et Stadhouders [33] ont décrit un procédé de fermentation du yoghourt entièrement continu, qui a été expérimenté avec succès à l'échelle pilote. Ce procédé comporte deux étapes, la première, comme précédemment, est une préfermentation du lait à $\mathrm{pH} 5,7$. La seconde se déroule dans une cuve de coagulation très élaborée comportant en particulier un système d'alimentation évitant le mélange brutal du lait préfermenté et du lait en cours de coagulation, et un système d'agitation fonctionnant en va-et-vient dans le fond de la cuve, selon le principe de la mouvette, pour donner au lait acidifié la consistance requise du yoghourt brassé.

Les avantages de ces procédés continus résultent évidemment de l'économie réalisée au niveau des investissements (place, cuves de fermentation et chambres étuves) et de la «productivité » d'une fermentation continue bien réglée. Les inconvénients de tels systèmes à l'échelle industrielle résultent des incidents de marche, par exemple des risques que font peser les attaques de bactériophages. 
La bonne marche d'une fermentation continue implique donc presque à coup sûr la mise en place d'une chaîne aseptique de fabrication ad hoc et exige une surveillance rigoureuse.

\section{B. LES FROMAGES A PATE CUITE}

\section{MECANISME DE L'EGOUTTAGE}

La fabrication de ce type de fromage débute par la coagulation du lait par la présure, c'est-à-dire la formation d'un réseau rassemblant la majeure partie des protéines du lait (les caséines). Ce coagulum est ensuite découpé, puis brassé mécaniquement et les grains de caillé sont soumis à un chauffage modéré à $53-56^{\circ} \mathrm{C}$. Ce travail du caillé en cuve a pour effet de provoquer un égouttage relativement rapide et important des grains, de telle sorte que, lorsque la masse de caillé est sortie de la cuve et mise sous presse, elle ne contient déjà plus que 50 p. 100 d'eau. La concentration correspondante en lactose du caillé est, dans ces conditions, suffisamment faible pour que ce sucre soit totalement fermenté en acide lactique. En outre, l'acidification sous presse favorise la synérèse du caillé et l'égouttage se poursuit de telle façon que le fromage est, si tout se passe bien, correctement égoutté (38-39 p. 100 d'eau) et acidifié ( $\mathrm{pH}$ voisin de 5,2$)$, lorsqu'il est sorti de la presse le lendemain de la fabrication.

En fait, l'acidification sous presse de ce type de fromage est une étape clé de la fabrication qui conditionne, pour une part essentielle, la réussite ou l'échec ultérieur de l'affinage. C'est aussi, nous allons le voir, une étape complexe qui n'a été bien comprise que récemment et qui constitue une bonne illustration de ce que peut être la fermentation lactique dans la pratique quotidienne de la fromagerie.

Lorsque le caillé est mis sous presse, sa température est voisine de $50^{\circ} \mathrm{C}$. La température ambiante de la salle de pressage étant nettement inférieure, la masse de caillé ( 50 à $80 \mathrm{~kg}$ ) va se refroidir. Comme cette masse est mauvaise conductrice de la chaleur, la température va chuter rapidement en périphérie alors qu'elle ne diminuera que lentement dans la zone centrale du fromage. Il va ainsi s'établir un gradient de température (fig. 4 a). En conséquence, la fermentation lactique va démarrer plus rapidement dans la zone périphérique, là où la température va se situer dans une zone favorable au développement et au métabolisme des bactéries lactiques. A l'inverse, dans la zone centrale, la température va demeurer trop élevée pendant les premières heures de pressage pour que la fermentation y démarre activement. Lorsqu'elle deviendra favorable, le levain ne disposera plus de lactose résiduel pour se développer. C'est ce qui explique les variations de développement du levain lactique observées par Accolas et al. [6], qui conduisent à des différences importantes et significatives (de l'ordre d'un log décimal) entre les populations bactériennes for- 

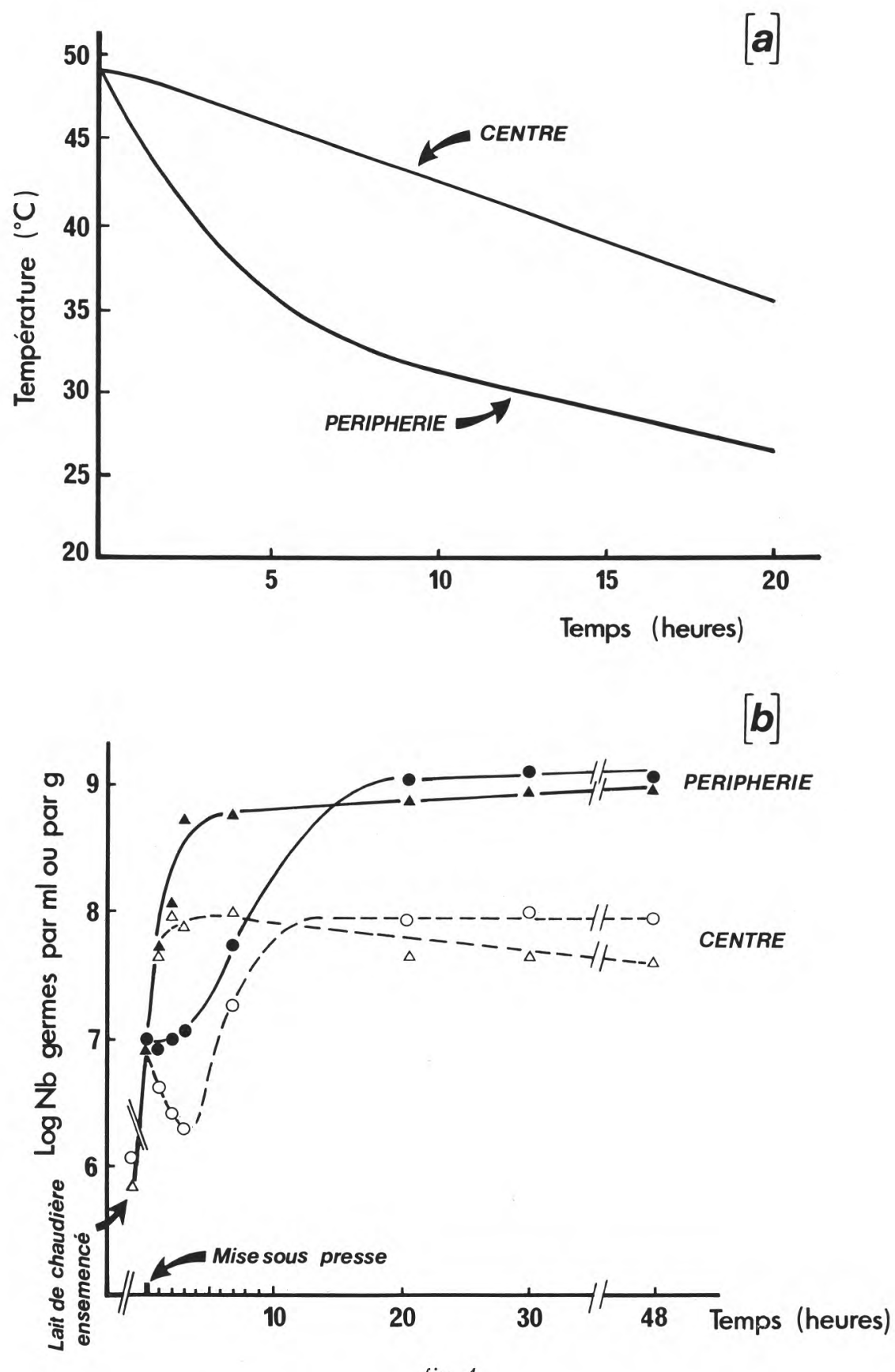

fig. 4

Comportement des fromages à pâte cuite pendant le pressage (d'après Accolas et al. [6])

a) Evolution des températures au centre et à la périphérie d'un fromage de Gruyère. Température ambiante : $24^{\circ} \mathrm{C}$.

b) Evolution de la flore lactique thermophile au cours des $48 \mathrm{~h}$ suivant la mise sous presse du gruyère. Dénombrements de L. helveticus au centre $(0-\mathrm{O})$ et à la périphérie $(\bullet-\bullet)$ du fromage ; dénombrements correspondants $(\triangle-\triangle)$ et $(\Delta--\Delta)$ de $S$. thermophilus. 
[a]
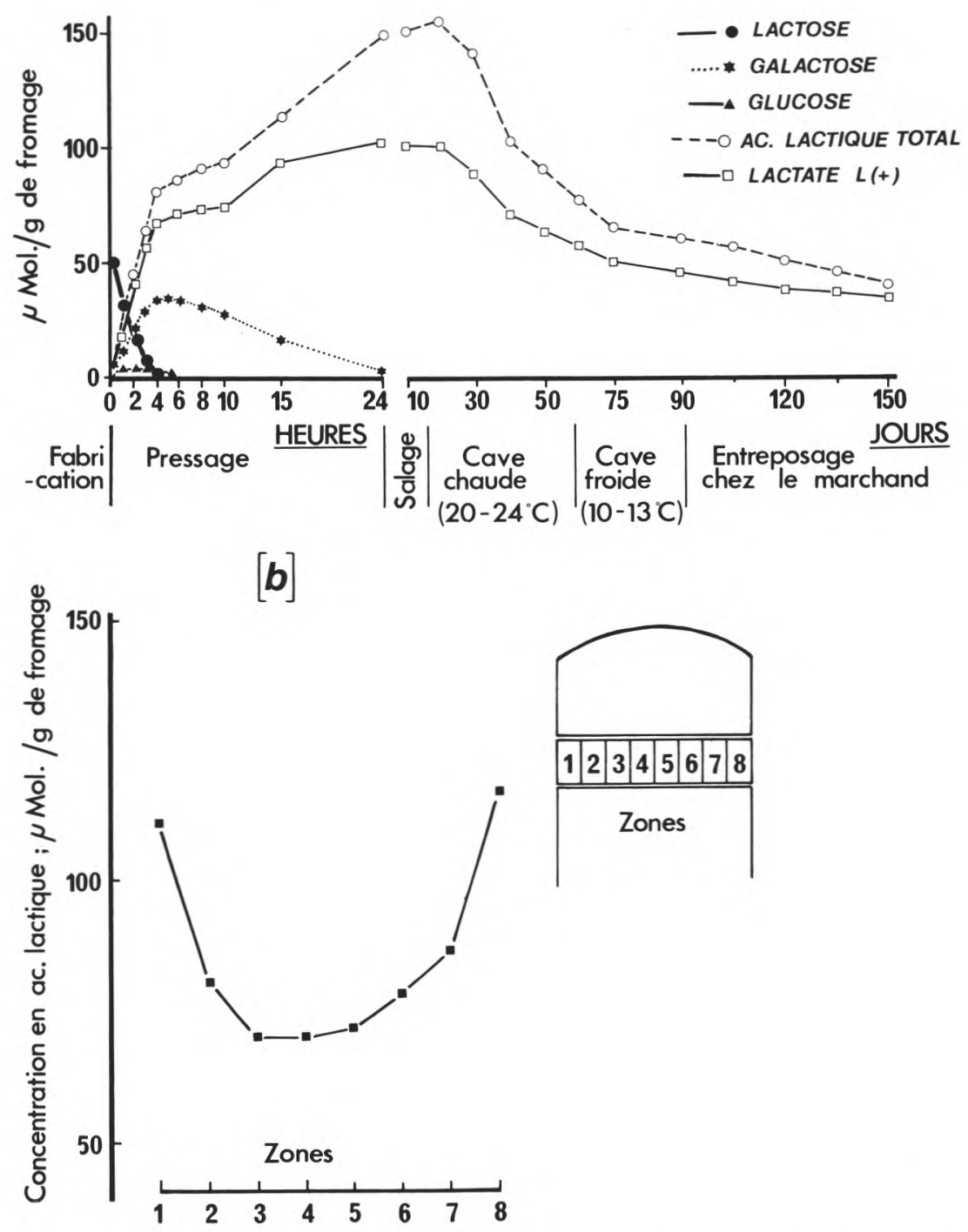

fig. 5

Comportement des fromages à pâte cuite sous presse et au cours de l'affinage (d'après STEFFEN $[88,92]$ )

a) Fermentation du lactose et formation du lactate au cours de la fabrication de l'emmental. Dégradation du lactate au cours de l'affinage.

b) Variations de la teneur en acide lactique suivant la zone du fromage, dans un emmental âgé de $24 \mathrm{~h}$. Les zones correspondant aux nombres indiqués en abscisse sont présentées sur la section schématique du fromage, dans la partie droite de la figure. 

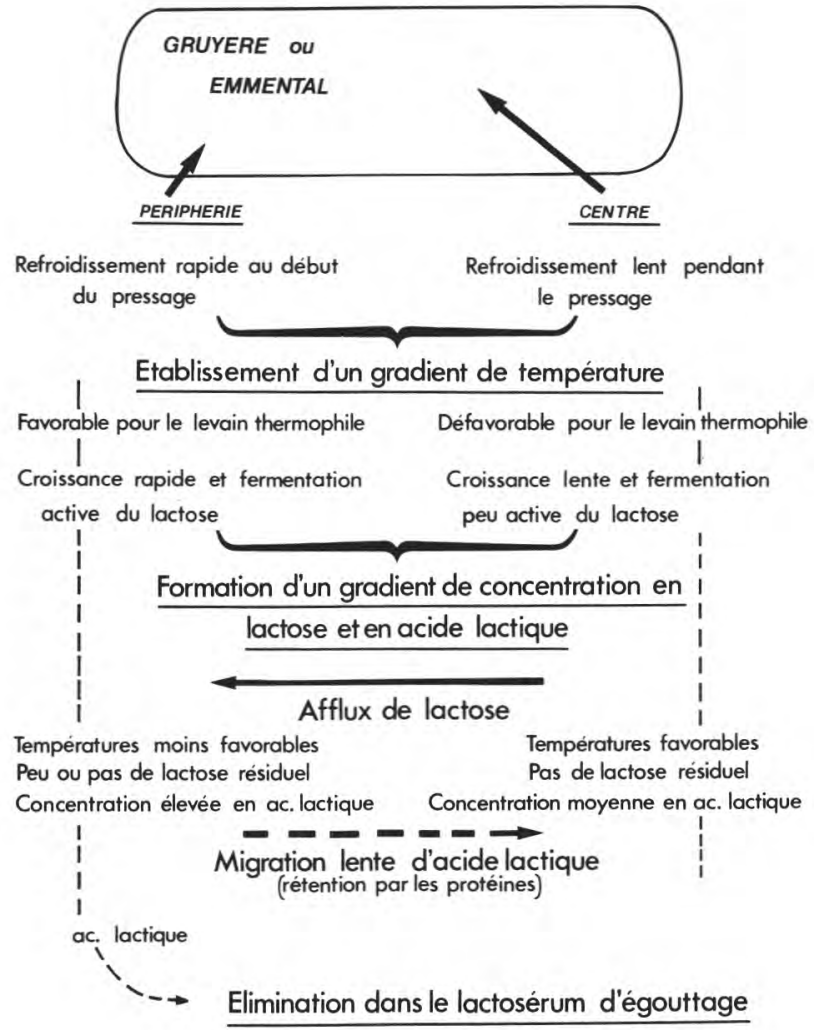

fig. 6

Schéma récapitulatif du comportement des fromages à pâte cuite sous presse, établi d'après les données d'Accolas et al. [6], de Mocouot [62] et de STEFFEN $[88,92]$

mées au centre et en périphérie d'un même fromage (fig. 4 b). En d'autres termes, la croissance des bactéries est plus rapide, la fermentation lactique plus intense et les populations finales atteintes plus élevées dans la zone périphérique que dans la zone centrale. L'étude de Steffen $[88,92]$ consacrée à l'évolution sous presse des teneurs en sucres (lactose, glucose et galactose) et des isomères de l'acide lactique en différents points du fromage, corrobore entièrement ces observations (fig. $5 \mathrm{a}$ et $\mathrm{b}$ ). Un tel phénomène est susceptible d'avoir des conséquences pratiques appréciables : il est possible, par exemple, qu'une répartition inégale des produits du métabolisme microbien dans les parties centrale et périphérique de la meule de fromage influe sur 
l'aspect (nombre et répartition des yeux) et sur diverses qualités organoleptiques du fromage affiné.

Cet ensemble de données bactériologiques et biochimiques a permis de proposer une interprétation cohérente du mécanisme de l'égouttage (Accolas et al. [6], Mocquot [62]) dont le bon déroulement constitue une étape clé de la réussite du fromage. On en trouvera une présentation schématique dans la figure 6.

\section{ROLE DU LEVAIN LACTIQUE THERMOPHILE AU COURS DE L'AFFINAGE}

Au cours de l'affinage du fromage, les bactéries lactiques thermophiles du levain qui étaient présentes en nombre élevé (mais variable suivant la zone du fromage) à la fin de la fabrication, vont disparaître soit rapidement ( $S$. thermophilus) soit plus lentement (lactobacilles), alors que d'autres micro-organismes, des lactobacilles mésophiles, des pédiocoques et, bien entendu, les bactéries propioniques responsables de la dégradation du lactate (fig. 5 a) et de la formation de l'ouverture, vont se développer dans le fromage (Veaux et al. [100], Steffen $[88,92]$, Steffen et al. [90]). Il a été suggéré de longue date que la diminution des bactéries du levain résultait de la lyse des cellules bactériennes et était accompagnée de la libération d'enzymes protéolytiques actives qui participaient, à des degrés divers, à l'affinage du fromage.

De nombreuses données expérimentales concourent à étayer cette façon de voir. Pour tenter d'en donner une présentation claire et concise, nous regrouperons ces données en deux chapitres.

\section{- Action protéolytique des bactéries lactiques thermophiles. Données générales}

De nombreux travaux ont été consacrés à l'étude des enzymes protéolytiques des bactéries lactiques thermophiles en relation, parfois avec le rôle éventuel de ces enzymes au cours de l'affinage du fromage. Nous ne reviendrons pas ici sur les travaux qui ont été passés en revue dans le chapitre consacré à la synergie des bactéries du yoghourt. Bornons-nous à compléter ce qui a été dit à cette occasion, en mentionnant par exemple le travail de Vescovo et Bottazzi [103] consacré aux caractéristiques et à la localisation du "système protéolytique " de souches de L. helveticus. Rappelons aussi le travail de Tourneur [96], déjà cité, où il apparaît que des lactobacilles thermophiles isolés du fromage ou du lactosérum (ceux du sous-groupe autrefois dénommé Thermobacterium) possèdent une activité protéasique supérieure à 
celle des autres lactobacilles, activité qui serait liée, pour une grande part, à la présence d'exo et d'endopeptidases localisées à la surface des cellules. D'autre part, il a été montré récemment que l'extrait brut intracellulaire de plusieurs souches de $S$. thermophilus déterminait in vitro une hydrolyse préférentielle de la caséine $\beta$ (Desmazeaud et Jugé [31]). La riche dotation en exopeptidases de nombreuses souches de $S$. thermophilus les rend potentiellement capables de dégrader certains peptides responsables de l'amertume. En particulier, leur capacité d'hydrolyser la liaison peptidique Pro-X (X étant un acide aminé variable) est à coup sûr aussi significative, de ce point de vue, qu'elle l'est dans le cas des streptocoques lactiques mésophiles (Mou et al. [65]). Cela contribue peut-être aussi à expliquer (au moins en partie) pourquoi l'amertume semble être un défaut de goût moins fréquent dans le cas des fromages à pâte cuite que dans le cas d'autres types de fromages (Pélissier et al. [69]). Notons aussi que de nombreuses souches de $S$. thermophilus possèdent une forte activité phosphatase acide, stable en fin de croissance (Bouillanne et Desmazeaud [18]). Cette observation présente un certain intérêt technologique si on la rapproche de celle de Dulley et Kitchen [34], qui ont montré qu'une activité phosphatase acide trop faible, au cours de la maturation du fromage, ralentissait la protéolyse et ne permettait pas d'obtenir un fromage affiné correct.

En ce qui concerne les lactobacilles, Ohmiya et Sato $[66,67]$ ont nettement mis en évidence l'action protéolytique des enzymes intracellulaires de L. helveticus en ajoutant des extraits cellulaires de ce germe à du caillé présure aseptique. Dans le même ordre d'idées, rappelons aussi que Petterson et Sjöström [72] ont obtenu des résultats expérimentaux satisfaisants (protéolyse plus précoce et plus intense ; bonne qualité organoleptique du fromage suédois à pâte semi-dure, une fois affiné) en ajoutant au lait de fromagerie des nombres élevés de lactobacilles thermophiles ayant subi un "choc thermique " préalable, destiné à réduire leur pouvoir acidifiant sans altérer leurs propriétés protéolytiques.

\section{- Action protéolytique du levain lactique thermophile au cours de l'affinage de l'emmental}

Une étude intensive des chercheurs suisses de Ia S.F.R.L. de Berne, s'appuyant en particulier sur une expérimentation fromagère répétée, a révélé sans ambiguïté possible le rôle de premier plan que joue le levain lactique thermophile au cours de l'affinage de l'emmental et, en conséquence, l'importance que revêt le choix du levain pour obtenir un fromage affiné sans défauts. Le premier objectif des chercheurs suisses était d'élucider le mécanisme de la fermentation dite secondaire ou tardive ( Nachgärung ») de l'emmental (Steffen [89]). Ce défaut d'ouverture caractéristique (lainure ouverte, yeux étirés, becs, etc.), qui 
déprécie fréquemment le fromage, est lié à une production intempestive de $\mathrm{CO}_{2}$ en fin d'affinage lorsque le fromage séjourne en cave froide, c'est-à-dire à une période où la pâte du fromage n'est plus assez élastique pour donner naissance à une ouverture normale.

Le levain lactique thermophile est impliqué, au premier chef, dans l'apparition de la fermentation secondaire (Steffen [91, 92]). Il existe en particulier un lien direct entre la nature du levain utilisé, son activité protéolytique et la formation de l'ouverture tardive. Il est par exemple remarquable que l'action protéolytique engendrée par des levains contenant $L$. helveticus est plus intense et, ce faisant, plus favorable à la fermentation secondaire que celle des levains contenant L. lactis $[52,90,93]$. Si le levain peut produire directement le $\mathrm{CO}_{2}$ indésirable [38], il favorise surtout (et cela de façon indirecte et inopportune) une production tardive de $\mathrm{CO}_{2}$ par la flore propionique. Il est donc clair que le choix des levains lactiques thermophiles utilisés pour fabriquer l'emmental, doit prendre en compte non seulement leur aptitude à produire l'acidification recherchée en fabrication, mais aussi des variations possibles, d'un levain à un autre, d'autres propriétés métaboliques, en particulier de l'aptitude à la protéolyse. A ce titre, la mesure de diverses activités enzymatiques dans le fromage peut fournir d'utiles indications sur le comportement du levain au cours de l'affinage $[80,90]$.

\section{BACTERIOPHAGES}

Il ne nous paraît pas utile de revenir ici longuement sur un problème qui a fait l'objet d'une discussion détaillée dans une revue précédente consacrée aux levains lactiques mésophiles (Cogan [24]). Bon nombre des problèmes que posent les bactériophages et les principes de lutte exposés dans cette synthèse sont certainement transposables aux levains lactiques thermophiles utilisés en technologie laitière.

Rappelons que les premiers accidents de fabrication où des phages spécifiques des bactéries lactiques thermophiles ont été mis en cause, ont été décrits dans les années 50 (Pette et Kooy [71], Deane et al. [25], Kiuru et Tybeck [49]) alors que les bactériophages des levains lactiques mésophiles étaient connus depuis les années 30 , grâce à la découverte des néo-zélandais Whitehead et Cox. Plus récemment, Reddy [76] a montré qu'en utilisant des techniques adéquates, il était possible de mettre en évidence, dans les usines employant des levains lactiques thermophiles, des phages spécifiques des bactéries du levain, $S$. thermophilus et lactobacilles, et cela, beaucoup plus fréquemment qu'on ne l'imaginait auparavant. 
Les phages de S. thermophilus isolés jusqu'à présent, appartiennent généralement à un type morphologique (tête isométrique, queue non contractile de longueur variable) qu'on trouve aussi fréquemment chez les phages des streptocoques lactiques mésophiles (Accolas et Spillmann [7]). Il est donc très possible, comme l'a remarqué Lawrence [55], qu'il existe un lien phylogénique entre les phages des streptocoques lactiques mésophiles et ceux de $S$. thermophilus. Les phages de $L$. bulgaricus et de L. lactis décrits actuellement sont, dans la majorité des cas, des phages du type morphologique précédent, à tête isométrique et à queue non contractile, tandis que ceux de L. helveticus possèdent une queue pourvue d'un manchon contractile (Accolas et Spillmann [8]).

Dans le cas des levains naturels des fromageries de gruyère, d'emmental, de sbrinz ou de grana, il est loisible de penser qu'on a affaire à des levains dont le comportement est similaire à celui des levains naturels mésophiles couramment utilisés en France et dans l'Europe septentrionale (Stadhouders [86], Stadhouders et al. [87]). Propagés dans les fromageries artisanales sans précautions rigoureuses d'asepsie, ces levains contiennent généralement, nous l'avons mentionné, une flore lactique thermophile diverse qui pourrait être soumise à une "pression sélective » continue par les phages présents dans la fromagerie, comme c'est le cas pour les levains lactiques mésophiles naturels (Stadhouders [86]). Avec ce type de levain, on s'expose à subir des irrégularités d'acidification, mais les accidents brutaux qui compromettent irrémédiablement la réussite du fromage, sont plutôt rares. Toutefois, l'utilisation empirique de levains naturels peut tout aussi bien entraîner l'apparition de phages lytiques et provoquer une acidification insuffisante en fabrication. En effet, Kurmann [51] a récemment montré que $S$. thermophilus et les lactobacilles thermophiles sont des bactéries lysogènes inductibles et que les levains lactiques thermophiles eux-mêmes représentent vraisemblablement la source des phages lytiques apparus dans les fromageries. Le problème ne diffère donc pas fondamentalement de celui que posent les levains lactiques mésophiles, si ce n'est que ce dernier est maintenant mieux connu (Lawrence [55], Lawrence et Thomas [56], Cogan [24]). Cela dit, l'emploi irréfléchi de cultures d'origine variée, en alternance ou en mélange, ne constitue certainement pas un remède aux difficultés causées par les phages. Bien au contraire, comme l'a remarqué Lawrence [55], cette pratique peut grandement favoriser l'apparition de phages lytiques. En outre, compte tenu de la concentration de la fabrication dans de grandes usines (c'est la règle pour le yoghourt et il existe maintenant de grandes fromageries d'emmental) on peut s'attendre à ce que le problème des phages des levains lactiques thermophiles se pose avec de plus en plus d'acuité dans l'avenir en raison de l'effet " amplificateur " de la taille de l'usine (Lawrence et Thomas [56]), surtout si le choix et la préparation des levains ne sont pas effectués avec toute l'attention et la réflexion nécessaires. 


\title{
Remerciements
}

Nous remercions bien vivement les revues: Journal of Dairy Science, LebensmittelWissenschaft und Technologie, Le Lait et Le Laitier Romand, de nous avoir aimablement autorisés à reproduire des figures extraites d'articles qu'elles ont publiés.

\section{R és u m é}

Cette revue est consacrée aux levains lactiques thermophiles. Une première partie traite du rôle de ces levains, des caractéristiques taxonomiques des espèces les plus représentatives ( $S$. thermophilus et lactobacilles) de la composition des différents types de levains et de leur utilisation sous forme concentrée et congelée ou lyophilisée.

Deux produits laitiers, le yoghourt et les fromages à pâte cuite choisis à titre d'exemple parce que les levains lactiques thermophiles y jouent un rôle de premier plan, sont l'occasion de discuter divers problèmes. Ainsi, dans le cas du yoghourt sont examinés successivement l'influence de la qualité du lait, la fermentation du lactose par $S$. thermophilus, la production d'arôme, la synergie des bactéries du yoghourt et la fermentation continue du lait à $\mathrm{pH}$ constant. Ensuite, le comportement des levains lactiques thermophiles au cours de la fabrication et de l'affinage des fromages à pâte cuite, est évoqué à la lumière des données expérimentales acquises et des hypothèses formulées récemment dans ce domaine. Un bref chapitre consacré aux bactériophages clôt cette revue.

\section{S u m m a r y}

\author{
THERMOPHILIC LACTIC STARTERS: \\ PROPERTIES AND BEHAVIOUR IN DAIRY TECHNOLOGY.
}

A REVIEW

The first part of this review deals with the role of thermophilic lactic starters, the taxonomy of the most representative species ( $S$. thermophilus and lactobacilli), the composition of various types of starters and the use of frozen and freeze-dried concentrates.

Various problems are discussed taking as examples yoghurt and hard cooked cheeses because of the major role played by the thermophilic starters in their manufacture. In the yoghurt the influence of milk quality, the lactose fermentation by $S$. thermophilus, the flavour production, the synergy between the yoghurt bacteria and the pH-stat continuous fermentation of milk are examined.

Then the behaviour of thermophilic lactic starters during the manufacture and ripening of hard cooked cheeses is discussed in the light of recent experimental data and new hypothesis in this field.

Finally data concerning thermophilic lactic phages are presented. 


\title{
Zusammenfassung
}

\author{
DIE THERMOPHILEN MILCHSAEUREWECKER : \\ EIGENSCHAFTEN UND VERHALTEN BEI DER MILCHVERARBEITUNG. \\ EINE UEBERSICHT
}

Diese UEbersicht handelt von den thermophilen Milchsäureweckern. Im ersten Teil werden die Rolle der Säurewecker, die taxonomischen Charakteristika der repräsentativsten Arten ( $S$. thermophilus und Lactobazillen), die Zusammensetzung der verschiedenen Säureweckertypen und ihre Verwendung in konzentrierter und tiefgefrorener oder gefriergetrockneter Form untersucht.

Als Beispiel wurden zwei Milchprodukte, Joghurt und Hartkäse ausgewählt, da bei ihnen die thermophilen Milchsäurewecker eine entscheidende Rolle spielen. Anhand dieser beiden Beispiele werden weitere Probleme diskutiert. So z.B. im Fall des Joghurts der Einfluß der Milchqualität, die Laktosegärung der $S$. thermophilus, die Aromabildung, die Synergie der Joghurtbakterien und die kontinuierliche Gärung der Milch bei konstantem $\mathrm{pH}$.

Im Falle der Hartkäse wird auf das Verhalten der thermophilen Milchsäurewecker im Laufe der Herstellung und Reifung von Hartkäse anhand von gewonnenen Untersuchungsdaten und neuesten Hypothesen auf diesem Gebiet eingegangen. Den Abschlu $\beta$ dieser UEbersicht bildet ein kurzer Abschnitt über Bakteriophagen.

Reçu pour publication en juillet 1980.

\section{Bibliographie}

[1] Accolas (J. P.) (1979). - Taxonomic features and identification of Lactobacillus bulgaricus and Streptococcus thermophilus. Rapport présenté au groupe F.I.L./I.D.F. E44 (Laits fermentés), Milan, 23 juillet.

[2] Accolas (J. P.) et Auclair (J.) (1964). - Etude bactériologique des levains utilisés dans la fabrication du gruyère. Annales de Technologie agricole (I.N.R.A.), 13, 85-96.

[3] Accolas (J. P.) et AuclatR (J.) (1970), - Détermination de l'activité acidifiante des suspensions concentrées et congelées de bactéries lactiques. Le Lait, 50, 609-626.

[4] Accolas (J. P.), Veaux (M.) et Auclair (J.) (1971). - Etude des interactions entre diverses bactéries lactiques thermophiles et mésophiles, en relation avec la fabrication des fromages à pâte cuite. Le Lait, 51, 249-272.

[5] Accolas (J. P.), Bloquel (R.), Didienne (R.) et Régnier (J.) (1977). - Propriétés acidifiantes des bactéries lactiques thermophiles en relation avec la fabrication du yoghourt. Le Lait, 57, 1-23.

[6] Accolas (J. P.), Veaux (M.), Vassal (L.) et Mocouot (G.) (1978). - Evolution de la flore lactique thermophile au cours du pressage des fromages à pâte cuite. Le Lait, 58, 118-132. 
[7] Accolas (J. P.) and Spillmann (H.) (1979). - The morphology of six bacteriophages of Streptococcus thermophilus. Journal of Applied Bacteriology, 47, 135-144.

[8] Accolas (J. P.) and SpillmanN (H.) (1979), - Morphology of bacteriophages of Lactobacillus bulgaricus, L. lactis and L. helveticus. Journal of Applied Bacteriology, 47, 309-319.

[9] Argyle (P. J.), Mathison (G. E.) and Chandan (R. C.) (1976). - Production of cell-bound proteinase by Lactobacillus bulgaricus and its location in the bacterial cell. Journal of Applied Bacteriology, 41, 175-184.

[10] Auclair (J.) (1964), - Les substances antibactériennes du lait cru et leur rôle en technologie laitière. 4th International Symposium on Food Microbiology, SIK, Göteborg (Suède), 281-296.

[11] Auclatr (J.) and Mocouot (G.) (1974). - Cultured milks. In milk products in the future, 33-36, J. Rothwell (Ed.), Society of Dairy Technology, UK.

[12] Bautista (E. S.), Dahiya (R.S.) and Speck (M. L.) (1966), - Identification of compounds causing symbiotic growth of Streptococcus thermophilus and Lactobacillus bulgaricus in milk. Journal of Dairy Research, 33, 289-307.

[13] Bills (D. D.), Yang (C. S.), Morgan (M. E.) and Bodyfelt (F. W.) (1972). Effect of sucrose on the production of acetaldehyde and acids by yoghurt culture bacteria. Journal of Dairy Science, 55, 1570-1573.

[14] Bottazzi (V.), Bersani (C.), Sarra (P. G.) e Magri (M.) (1977). - Caratteristiche dei bacilli lattici presenti nelle colture naturali in siero. 1. Tassonomia, morfologia, attività da $\beta$-galattosidasi e da latticodeidrogenasi. Scienza e Tecnica Lattiero-casearia, 28, 430-442.

[15] Bottazzi (V.), Sarra (P. G.), Vescovo (M.) e Bersani (C.) (1978), - Caratteristiche dei bacilli lattici presenti nelle colture naturali in siero. 4. Saggi per la caratterizzazione delle colture. Scienza e Tecnica Lattiero-casearia, $29,367-381$.

[16] Boutllanne (C.), Landon (M.), Auclair (J.) and Mocouot (G.) (1978). Characteristics of concentraded freeze-dried bacterial suspensions prepared from cultures of mixed strains of lactic acid bacteria from commercial starters. Proceedings of the International Meeting on Food Microbiology and Technology. Tabiano B. (Parma) Italy (April 20-23), 89-94.

[17] Boutllanne (C.) et Auclatr (J.) (1978). - Préparation de suspensions concentrées lyophilisées de bactéries lactiques pour la fromagerie. 20 Congrès International de Laiterie, brèves communications (F), 595-596.

[18] Bouillanne (C.) et Desmazeaud (M. J.) (1980). - Etude de quelques caractères de souches de Streptococcus thermophilus utilisées en fabrication de yaourts et proposition d'une méthode de classement. Le Lait, 60, 458-473.

[19] BRacoutart (P.) et LoRIEnt (D.) (1977). - Effet des acides aminés sur la croissance de Streptococcus thermophilus. Milchwissenschaft, 32, 221-224.

[20] BRacouart (P.), LORIENT (D.) et Alais (C.) (1978). - Effet des acides aminés sur la croissance de Streptococcus thermophilus. II. Etude sur cinq souches. Milchwissenschaft, 33, 341-344.

[21] BRacouart (P.) et LoRIEnt (D.) (1979). - Effet des acides aminés et peptides sur la croissance de Streptococcus thermophilus. III. Peptides comportant Glu, His et Met. Milchwissenschaft, 34, 676-679.

[22] CaRini (S.) et Lodi (R.) (1978), - Les bactéries lactiques dans les levains naturels et sélectionnés. $20^{\circ}$ Congrès International de Laiterie, brèves communications (F.), 537-538. 
[23] COGAN (T. M.) (1972). - Susceptibility of cheese and yoghurt starter bacteria to antibiotics. Applied Microbiology, 23, 960-965.

[24] Cogan (T. M.) (1980). - Levains lactiques mésophiles. Une revue. Le Lait, $60,397-425$.

[25] Deane (E.), Nelson (F. E.), Ryser (F. C.) and Carr (P. H.) (1953). - Streptococcus thermophilus bacteriophage from Swiss cheese whey. Journal of Dairy Science, 36, 185-196.

[26] Dellaglio (F.), Botrazzi (V.) and Trovatelli (L. D.) (1973). - Deoxyribonucleic acid homology and base composition in some thermophilic lactobacilli. Journal of General Microbiology, 74, 289-297.

[27] Desmazeaud (M. J.) (1974). - Propriétés générales et spécificité d'action d'une endopeptidase neutre intracellulaire de Streptococcus thermophilus. Biochimie, 56, 1173-1181.

[28] Desmazeaud (M. J.) et Devoyod (J. J.) (1970). - Action stimulante des microcoques caséolytiques sur les bactéries lactiques thermophiles. Mise en évidence de la nature peptidique des substances stimulantes. Annales de Biologie animale, Biochimie, Biophysique, 10, 413-430.

[29] Desmazeaud (M. J.) et Hermier (J.) (1972). - Isolement et détermination de la composition qualitative de peptides issus de la caséine, stimulant la croissance de Streptococcus thermophilus. European Journal of Biochemistry, 28, 190-198.

[30] Desmazeaud (M. J.) et Hermier (J.) (1973), - Effet de fragments peptidiques du glucagon vis-à-vis de la croissance de Streptococcus thermophilus. Biochimie, 55, 679-684.

[31] Desmazeaud (M. J.) et JugÉ (M.) (1976). - Caractérisation de l'activité protéolytique et fractionnement des dipeptidases et des aminopeptidases de Streptococcus thermophilus. Le Lait, 56, 241-260.

[32] Driessen (F. M.), Ubbels (J.) and Stadhouders (J.) (1977). - Continuous manufacture of yoghurt. I. Optimal conditions and kinetics of the prefermentation process. Biotechnology and Bioengineering, 19, 821-839.

[33] Driessen (F. M.), Ubbels (J.) and Stadhouders (J.) (1977) . - Continuous manufacture of yoghurt. Procedure and apparatus for continuous coagulation. Biotechnology and Bioengineering, 19, 841-851.

[34] Dulley (J. R.) and Kitchen (B. J.) (1973). - The acid phosphatases of cheddar cheese. The Australian Journal of Dairy Technology, 28, 114-116.

[35] Dumont (J. P.) et AdDA (J.) (1973). - Méthode rapide d'étude des composés très volatils de l'arôme des produits laitiers. Applications au yoghourt. Le Lait, 53, 12-22.

[36] Dumont (J. P.) and ADDA (J.) (1979). - Flavour formation in dairy products. In Progress in Flavour Research, 245-262, D.G. Land and H. E. Nursten (Eds), Applied Science Publishers Ltd. Barking, Essex, G.-B.

[37] EL Soda (M.) (1980). - Les peptidehydrolases des lactobacilles. Caractérisation de ces enzymes chez Lactobacillus casei. Thèse de doctorat ès sciences, Université Paris VII (France).

[38] Flückiger (E.) und Walser (F.) (1977). - Beitrag zur Kenntnis der $\mathrm{CO}_{2}$ Bildung von Rohmischkulturen. Schweizerische Milchzeitung, 103 (76), 640-641.

[39] Galesloot (T. E.), Hassing (F.) and Veringa (H. A.) (1968). - Symbiosis in yoghurt. I. Stimulation of Lactobacillus bulgaricus by a factor produced by Streptococcus thermophilus. Netherlands Milk and Dairy Journal, 22, 50-63. 
[40] Galesloot (T. E.) and Hassing (F.) (1973). - Further investigations concerning the consistency of yoghurt. Nizo-Mededelingen, 7, 15-33.

[41] Galesloot (T. E.) and Hassing (F.) (1973), - Maintaining the slime production of yoghurt cultures. Nizo-Mededelingen, 7, 57-62.

[42] GoRDON (J.F.) and SHAPTON (N.) (1977) - Characteristics and use of starters for the manufacture of yoghurt, cottage cheese, cultured buttermilk and other fermented products. Journal of the Society of Dairy Technology, 30, 15-22.

[43] Hamdan (I. Y.), Kunsman (J. E.) and Deane (D. D.) (1971). - Acetaldehyde production by combined yoghurt cultures. Journal of Dairy Science, 54, 1080-1082.

[44] Hemme (D.), Vassal (L.), Foyen (H.) et Auclair (J.) (1979). - Effet de l'addition de lactase au lait sur le développement des lactobacilles et des streptocoques thermophiles. Le Lait, 59, 597-614.

[45] Hemme (D.) et NaRdi (M.) (1980). - Electrophorégrammes des protéines, de la $\beta$-galactosidase et de l'aldolase de Streptococcus thermophilus et des lactobacilles thermophiles. Leurs variations selon les souches et les conditions de culture. Le Lait, 60, 375-392.

[46] Hemme (D.), Schmal (V.) and Auclair (J.) (1980), - Effect of the addition of extracts of thermophilic lactobacilli on acid production by Streptococcus thermophilus in milk. Journal of Dairy Research (sous presse).

[47] Hemme (D.), Wahl (D.) et Nardi (M.) (1980). - Variations de l'équipement enzymatique de Streptococcus thermophilus. Le Lait, 60, 111-129.

[48] Higashió (K.), Kikuchi (T.) et Furuichi (E.) (1978). - Symbiose entre Lactobacillus bulgaricus et Streptococcus thermophilus dans le yoghourt. $20^{\mathrm{e}}$ Congrès International de Laiterie, brèves communications (F), 522-523.

[49] KIURU (V. J. T.) and TrBecK (E.) (1955). - Characteristics of bacteriophages active against lactic acid bacteria in Swiss cheese. Suomen Kemistilehti, B 28, 57-62.

[50] KNITTEL (M. D.) (1965). - Genetic homology and exchange in lactic acid streptococci. Ph. D. Thesis, Oregon State University, U.S.A.

[51] KuRmanN (J.L.) (1979). - Bakteriophagenbedingte Säuerungsstörungen in Hartkäserein. Schweizerische Milchwirtschaftliche Forschung, 8, 71-76.

[52] Lavanchy (P.), Buhlmann (C.), Blanc (B.) (1978). - Influence de diverses cultures lactiques thermophiles sur la protéolyse du fromage d'emmental. $20^{\circ}$ Congrès International de Laiterie, brèves communications $(\mathrm{F}), 491$.

[53] Law (B. A.), Castanon (M. J.) and Sharpe (M. E.) (1976). - The contribution of starter streptococci to flavour development in cheddar cheese. Journal of Dairy Research, 43, 301-311.

[54] LAW (B. A.) and SHARPE (M. E.) (1978). - Streptococci in the dairy industry. In Streptococci, 263-278, F. A. Skinner and L. B. Quesnel (Eds). The Society for Applied Bacteriology, Symposium Series $n^{\circ}$ 7. Academic Press, London - New York - San Franscisco.

[55] LaWRENCE (R. C.) (1978). - A lecture: action of bacteriophages on lactic acid bacteria. Consequences and protection. 20 Congrès International de Laiterie, Scientific and Technical Sessions (2 ST), 15.

[56] LaWREnCE (R. C.) and Thomas (T. D.) (1979). - The fermentation of milk by lactic acid bacteria. In Microbial technology: current state, future prospects, 29th Symposium of the Society of General Microbiology, 187-219, A. T. Bull, D. C. Ellwood and C. Ratledge (Eds).

[57] LeEs (G. J.) and JAGo (G. R.) (1978). - Role of acetaldehyde in metabolism: A review. 2 . The metabolism of acetaldehyde in cultured dairy products. Journa! of Dairy Science, 61, 1216-1224. 
[58] Lelieved (H. L. M.) (1976). - Continuous fermentation in yoghurt manufacture. Process Biochemistry, 11 (5), 39-40.

[59] Lorient (D.), Bracouart (P.) et Alais (C.) (1977), - Dégradation thermique des caséines $\alpha_{s}$ et $\beta$ de vache. IV. Substances peptidiques libérées. Propriétés activatrices de la croissance des bactéries lactiques. Annales de Biologie animale, Biochimie, Biophysique, 17, 215-235.

[60] Macbean (R. D.), Hall (R. J.) and Linklater (P. M.) (1979). - Analysis of $\mathrm{pH}$-stat continuous cultivation and the stability of the mixed fermentation in continuous yoghurt production. Biotechnology and Bioengineering, $21,1517-1541$.

[61] Miller (I.) and Kandler (O.) (1967). - Proteolysis and liberation of free amino acids by lactic acid bacteria in milk. I. Changes of the $\mathrm{N}$ fractions. Milchwissenschaft, 22, 150-159.

[62] Mocovot (G.) (1979). - Reviews of the progress of dairy science: Swiss-type cheese. Journal of Dairy Research, 46, 133-160.

[63] Mocouot (G.) and Hurel (C.) (1970). - The selection and use of some micro-organisms for the manufacture of fermented and acidified milk products. Journal of the Society of Dairy Technology, 23, 130-146.

[64] Morichi (T.) (1974). - Preservation of lactic acid bacteria by freeze-drying. Japan Agricultural Research Quarterly, 8, 171-176.

[65] Mou (L.), Sullivan (J. J.) and JAGo (G. R.) (1975). - Peptidases activities in group N streptococci. Journal of Dairy Research, 42, 147-155.

[66] Ohmiya (K.) and Sato (Y.) (1970). - Studies on the proteolytic action of dairy lactic acid bacteria. X. Autolysis of lactic acid bacteria cells in aseptic rennet curd. Agricultural and Biological Chemistry, 34, 457-463.

[67] Ohmiya (K.) and Sato (Y.) (1970). - Studies on the proteolytic action of dairy lactic acid bacteria. XI. The ripening of aseptic rennet curd. Agricultural and Biological Chemistry, 34, 1463-1469.

[68] Ottogalli (G.), Galli (A.) and Dellaglio (F.) (1979). - Taxonomic relationships between Streptococcus thermophilus and some other streptococci. Journal of Dairy Research, 46, 127-131.

[69] Pélissier (J. P.), Mercier (J. C.) et Ribadeau-Dumas (B.) (1974). - Problème de l'amertume dans les fromages. Résultats d'une enquête. Revue Laitière Française, 325, 817-821.

[70] Pette (J. W.) and Lolkema (H.) (1950). - Yoghurt. I. Symbiosis and antibiosis in mixed cultures of Lb. bulgaricus and Sc. thermophilus. Netherlands Milk and Dairy Journal, 4, 209-224.

[71] PetTe (J. W.) and Kooy (J. S.) (1952). - Bacteriophages in yoghurt. Netherlands Milk and Dairy Journal, 6, 233-241.

[72] Pettersson (H. E.) and S.öström (G.) (1975). - Accelerated cheese ripening: a method for increasing the number of lactic starter bacteria in cheese without detrimental effect to the cheese-making process, and its effect on the cheese ripening. Journal of Dairy Research, 42, 313-326.

[73] Portmann (A.), Gaté (Y.) et Auclair (J.) (1962). - Influence de la lactoperoxydase et des agglutinines du lait sur l'activité des bactéries des levains thermophiles. 16 ${ }^{\mathrm{e}}$ Congrès International de Laiterie, B, 729-736.

[74] Porubcan (R. S.) and Sellers (R. L.) (1975). - Spray drying of yoghurt and related cultures (abstract). Journal of Dairy Science, 58, 787.

[75] Rabier (D.) et Desmazeaud (M. J.) (1973). - Inventaire des différentes activités peptidasiques intracellulaires de Streptococcus thermophilus. Purification et propriétés d'une dipeptidohydrolase et d'une aminopeptidase. Biochimie, 55, 389-404. 
[76] REDDy (M. S.) (1974). - Development of cultural techniques for the study of Streptococcus thermophilus and Lactobacillus bacteriophages. Ph. D. Thesis, Iowa State University, U.S.A.

[77] Robinson (R. K.) and Tamine (A. Y,) (1975), - Yoghurt. A review of the product and its manufacture. Journal of the Society of Dairy Technology, 28, 149-163.

[78] Rogosa (M.) (1974). - Genus Lactobacillus. In Bergey's Manual of Determinative Bacteriology, 8th ed., 576-593, R. E. Buchanan and N. E. Gibbons (Eds), Williams and Wilkins Co., Baltimore, Maryland, U.S.A.

[79] Rousseaux (P.), Vassal (L.), Valles (E.), Auclair (J.) et Mocouot (G.) (1978). - Utilisation en fromagerie de gruyère de suspensions concentrées congelées de bactéries lactiques thermophiles. Le Lait, 48, 241-254.

[80] Schaer (H.), Kaufmann (H.) und Nick (B.) (1979). - Prüfung thermophiler Milchsäurebakterien. Kulturen (Rohmischkulturen) für die Emmentalerfabrikation in Käsungsversuchen. Sweizerische Milchzeitung, 105 (18), 114-116.

[81] Shankar (P. A.) et Davies (F. L.) (1978). - Activités protéinasique et peptidasique des bactéries du yoghourt. $20^{\circ}$ Congrès International de Laiterie, brèves communications ( $\mathrm{F}$.), 473.

[82] Shankar (P.A.) et Davies (F. L.) (1978). - Relation entre Streptococcus thermophilus et Lactobacillus bulgaricus dans les levains du yoghourt.

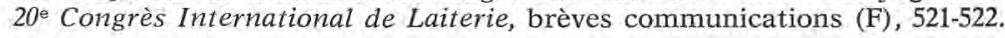

[83] Smittle (R. B.), Gilliland (S. E.) and Speck (M. L.) (1972). - Death of Lactobacillus bulgaricus resulting from liquid nitrogen freezing. Applied Microbiology, 24, 551-554.

[84] Somkuti (G. A.) and Steinberg (D. H.) (1979). - Adaptability of Streptococcus thermophilus to lactose, glucose and galactose. Journal of Food Protection, 42, 885-887.

[85] SPECKMAN (C. A.) (1975). - Preparation, evaluation, and use of lyophilized concentrated dairy starter cultures in cheese and yoghurt manufacture. Ph. D. Thesis, Oregon State University, U.S.A.

[86] Stadhouders (J.) (1975). - A lecture: microbes in milk and dairy products. An ecological approach. Netherlands Milk and Dairy Journal, 29, 104-126.

[87] Stadhouders (J.), Bangma (A.) and Driessen (F. M.) (1975). - Control of acid production in cheese manufacture. Nizo-nieuws, $\mathrm{n}^{\circ \mathrm{s}} 11$ and 12.

[88] STEFFen (C.) (1975). - Enzymatische Bestimmungsmethoden zur Erfassung der Gärungsvorgänge in der milchwirtschaftlichen Technologie. Lebensmittel-Wissenschaft und-Technologie, 8, 1-6.

[89] StefFen (C.) (1976). - Praktische Ueberlegungen zu den Ursachen der Nachgärung und deren Bekämpfung im Emmentalerkäse. Schweizerische Milchwirtschaftliche Forschung, 5, 43-50.

[90] StefFen (C.), Glaettli (H.) und Nick (B.) (1979). - Vergleichende Untersuchungen von Käsen mit und ohne Nachgärung. III. Bakteriologische und enzymatische Untersuchungen. Schweizerische Milchwirtschaftliche Forschung, 8, 19-26.

[91] STEFFEN (C.) (1979). - Vergleichende Untersuchungen in Emmentalerkäsen mit und ohne Nachgärung. VI. Schlussfolgerungen. Schweizerische Milchwirtschaftliche Forschung, 8, 44-48.

[92] STEFFEN (C.) (1979), - La fabrication du fromage et la recherche fromagère en Suisse. Le Laitier Romand, 105 (73), 501-503. 
[93] Steiger (G.) und Flückiger (E.) (1979). - Vergleichende Untersuchungen in Emmentalerkäsen mit und ohne Nachgärung. Schweizerische Milchwirtschaftiche Forschung, 8, 39-43.

[94] Tamine (A. Y.) (1977). - The behaviour of different starter cultures during the manufacture of yoghurt from hydrolysed milk. Dairy Industries International, 42, 7-11.

[95] Terzaghi (B. E.) and Sandine (W. E.) (1975). - Improved medium for lactic streptococci and their bacteriophages. Applied Microbiology, 29, 807-813.

[96] Tourneur (C.) (1972). - Aptitude à la protéolyse des lactobacilles présents dans les fromages et les lactosérums de fromagerie. Le Lait, 52, 149-174.

[97] Tramer (J.) (1973). - Yoghurt cultures. Journal of the Society of Dairy Technology, 26, 16-21.

[98] Valles (E.) et Mocouot (G.) (1972). - Etude de la technique de préparation de la présure utilisée dans les fabrications traditionnelles de fromages de gruyère, de comté et d'emmental. Le Lait, 52, 259-283.

[99] VASSal (L.) et Auclair (J.) (1966). - Variations de la production d'acide par les bactéries du yoghourt dans les laits de grand mélange. 17 Congrès International de Laiterie, $E / F, 669-676$.

[100] Veaux (M.), Accolas (J. P.), Vassal (L.) et Auclair (J.) (1974). - Evolution des bactéries lactiques et des bactéries propioniques au cours de la fabrication et de l'affinage du gruyère. 19e Congrès International de Laiterie, 1 F, 458-459.

[101] Veringa (H. A.), Galesloot (T. E.) and Davelaar iH.) (1968). - Symbiosis in yoghurt. II. Isolation and identification of a growth factor for Lactobacillus bulgaricus produced by Streptococcus thermophilus. Netherlands Milk and Dairy Journal, 22, 114-120.

[102] Veringa (H. A.) (1973). - Biochemical processes in the production of yoghurt. Nizo-Mededelingen, 7, 88-96.

[103] Vescovo (M.) e Bottazzi (V.) (1979). - Caratteristiche dei bacilli battici presenti nelle colture naturali in siero. 6. Localizzazione citologica del sistema proteolitico in $L$. helveticus. Scienza e Tecnica Lattiero-casearia, 30, 434-443. 